\title{
OCUPACIÓN Y USO DEL TERRITORIO EN EL SECTOR CENTROMERIDIONAL DE LA CUENCA DEL DUERO ENTRE LA ANTIGÜEDAD Y LA ALTA EDAD MEDIA (SIGLOS I-XI D.C.)
}

\author{
OCCUPATION AND LAND USE IN THE CENTRAL- \\ SOUTHERN SECTOR OF THE DUERO BASIN BETWEEN \\ ANTIQUITY AND THE EARLY MIDDLE AGES \\ ( $1^{\mathrm{ST}}$ TO $11^{\mathrm{TH}}$ CENTURIES A.D.)
}

\author{
ANTONIO BLANCO GONZÁLEZ \\ Dirección General de Patrimonio Cultural. Junta de Castilla y León \\ JOSÉ ANTONIO LÓPEZ SÁEZ y LOURDES LÓPEZ MERINO \\ G.I. Arqueobiología. Instituto de Historia, CCHS, CSIC
}

\section{RESUMEN}

Los autores plantean una lectura de síntesis sobre las dinámicas de asentamiento y explotación de los territorios comprendidos entre el Sistema Central y las campiñas al sur del río Duero entre la implantación romana y los momentos altomedievales. Para estudiar el poblamiento se ha recurrido a los datos de prospección extensiva de los inventarios provinciales, con el concurso de los resultados de recientes excavaciones en yacimientos rurales y urbanos. A partir de esta información arqueológica se ha ensayado una evaluación cuantitativa de los usos del suelo en el Valle Amblés (Ávila), midiendo los territorios de explotación de algunos sitios mediante un Sistema de Información Geográfica. Se integra la información paleopalinológica procedente tanto de sondeos en turberas como de muestreos en yacimientos excavados. El trabajo atiende a la transformación de las pautas agropastoriles desde la colonización altoimperial y hasta la ocupación aldeana de comienzos del Medievo, siguiendo unos ejes diacrónicos que pivotan sobre la proliferación del hábitat rural, la creciente intensificación agraria y la especialización productiva.

\section{SUMMARY}

The authors propose an overview of the dynamics of settlement and land use in the region between the Central System and the territory south of the Duero River. The time span is the period between the Roman establishment and the Early Middle Ages. In order to study the settlement patterns, data from a field survey contained in the provincial inventories have been used. In addition, information from recent excavations in rural and urban sites has also been taken into account. Based on this data, a quantitative evaluation of land use in the Amblés Valley (Ávila) has been attempted. To do so, Geographical Information Systems have been applied in order to measure land exploitation. As a complement, palaeopalynological data both from peat bogs and from samples from archaeolog- ical sites have been added. The paper focuses on the agropastoral transformations that took place from the Flavian colonization up to the Early Middle Ages. The main aspects discussed following a diachronic point of view are: the spread of the rural habitat, the increasing agrarian intensification and the growing specialization of production.

PALABRAS CLAVE: Poblamiento romano, tardoantiguo y altomedieval, análisis palinológicos, análisis de territorios de explotación, Sistema de Información Geográfica, Submeseta Norte.

KEY WORDS: Late Antiquity and Early Medieval Roman settlement, pollen analysis, site exploitation analysis, Geographic Information System, Northern Plateau.

\section{INTRODUCCIÓN}

La evaluación de los sistemas de poblamiento y explotación de territorio, en la transición entre la Antigüedad y el Medievo, se está convirtiendo en un foco prioritario en la investigación arqueológica, por proveer de informaciones relevantes sobre los profundos cambios que caracterizan tal coyuntura (Hamerow 2002: 52-124; Wickham 2005: 259-264). En este trabajo se avanza un esbozo de la dinámica del asentamiento y su correspondiente impacto en los paisajes vegetales a lo largo de diez siglos ${ }^{1}$. Se ha

1 Todas las fechas mencionadas en el texto pertenecen a nuestra era — salvo indicación expresa de lo contrario-. Las fechas de calendario, obtenidas a partir de la calibración del radiocarbono, se acompañan de la expresión cal AD. 
elegido este intervalo temporal por ser lo suficientemente amplio como para asistir al reemplazo de las estructuras sociales y políticas antiguas por otras de tipo feudal. El interés por enfocar el análisis en esta zona del interior peninsular viene determinado por las peculiaridades de las tierras entre el Duero y el Sistema Central, con un proceso histórico afectado por claras rupturas sociopolíticas y que adolece de una escasa contrastación entre el discurso histórico y un registro arqueológico sólo incipientemente sistematizado. Por encima de sus carencias, para la zona y el tramo cronológico elegidos, disponemos sin embargo de indicios relevantes que jalonan e iluminan el proceso. Se trata de informaciones dispersas y heterogéneas que permiten una puesta en común. Nuestra pretensión es pues plantear un marco interpretativo provisional, que a modo de esquema de trabajo - ni siquiera formalizado como hipótesisrecoja tales informaciones y las organice en un discurso coherente. Sin duda futuros estudios se encargarán de refutar o matizar esta línea argumental, afinando cronologías y completando las lagunas.

Para ello se recurre a un enfoque a distintas escalas, aplicando metodologías de intensidad y resolución variadas, en un intento de integrar informaciones complementarias sobre esta compleja realidad. Por una parte se efectúa una lectura del registro arqueológico, desde los datos de excavaciones - en gran parte inéditas, fruto de actividades preventivas tuteladas por la administración — hasta la dinámica del poblamiento rural a partir de prospecciones extensivas. Por otra parte se recurre a informaciones respecto al impacto antrópico sobre las formaciones vegetales y las pautas de uso del suelo, mediante los registros palinológicos —obtenidos sobre contextos arqueológicos o en depósitos naturales higroturbosos- y explorando la propia información territorial de los asentamientos mediante un SIG.

\section{1. ÁREA DE TRABAJO}

Para aproximarnos a la problemática expuesta, hemos seleccionado un espacio de trabajo rectangular de unos $7.680 \mathrm{~km}^{2}$, definido sobre el contorno de quince hojas del Mapa Topográfico Nacional a escala 1:50.000 y que abarca parte de las provincias de Valladolid, Salamanca, Ávila y Segovia. En este territorio quedan comprendidas tanto las campiñas sedimentarias al sur del río Duero - representadas por las unidades paisajísticas de La Moraña, la Tierra de Medina y la Tierra de Pinares- como los bloques medios y bajos del Sistema Central — con las cadenas montañosas de la Sierra de Ávila, las Parameras, la Sierra de Ojos Albos y la Sierra de Guadarrama- así como el valle intramontañoso del Amblés (Fig. 1).

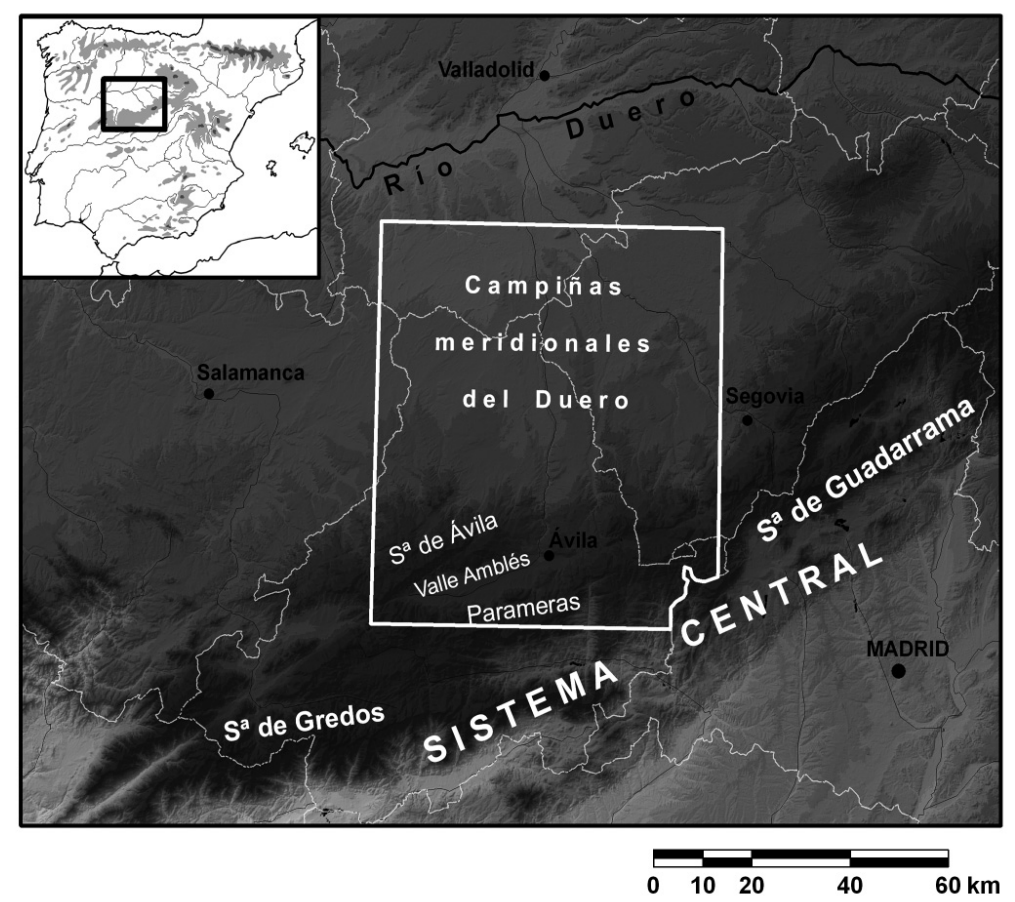

Figura 1. Situación del área de trabajo en el sur de la Submeseta Norte. 
Se trata de un territorio que, si bien pudo quedar repartido entre varias circunscripciones administrativas, responde a una evolución política homogénea, tanto bajo el dominio romano como durante el reinado visigodo y, especialmente tras la disolución de éste, permanece como un territorio intersticial desorganizado, entre los dos más dinámicos focos al sur del Duero que lo rodean, a Oriente y Occidente. En su interior encontramos además unidades ecológicas suficientemente contrastadas y de acusada personalidad geográfica como para comprobar la complementariedad entre las campiñas, los valles y las sierras, de usos agroganaderos y forestales tradicionales bien imbricados (Clément 2002: 56-67).

\section{EVOLUCIÓN DEL POBLAMIENTO}

El estudio de la ocupación del territorio se ha basado en los datos recuperados en las sucesivas campañas de prospección extensiva o selectiva para elaborar el Inventario Arqueológico de Castilla y León —en adelante IACyL - en las cuatro provincias incluidas en nuestra zona de trabajo ${ }^{2}$. La caracterización de cada momento se ha apoyado en los datos de las excavaciones arqueológicas efectuadas o en curso de realización, así como en la bibliografía existente al respecto.

El tipo de informaciones recopiladas y el propio estado de los debates historiográficos han aconsejado agrupar los datos sobre el poblamiento en clasificaciones que atienden fundamentalmente al material arqueológico al que se asocian y a grandes hitos históricos muy generales, entre los cuales se sitúan. Así, si bien la referencia a las etapas altoimperial y tardoromana no plantea excesivos problemas, las atribuciones crono-culturales visigoda y altomedieval son en cambio un convencionalismo muy polisémico, sin traducción directa a una lectura histórica.

A modo de introducción, una evaluación preliminar del poblamiento a partir de los datos de prospección extensiva disponibles (Fig. 2) permite efectuar dos afirmaciones. La primera pasa por caracterizar el primer milenio d.C. por la progresiva y definitiva implantación y ocupación integral del territorio estudiado. Desde un punto de partida en el Hierro II,

2 Un listado inicial de yacimientos nos fue facilitado desde la Dirección General de Patrimonio Cultural de la Junta de Castilla y León. Posteriormente, en los Servicios Territoriales de Cultura de Valladolid, Salamanca, Ávila y Segovia procedimos a revisar las fichas actualizadas de yacimientos, así como algunas memorias técnicas de excavaciones arqueológicas.

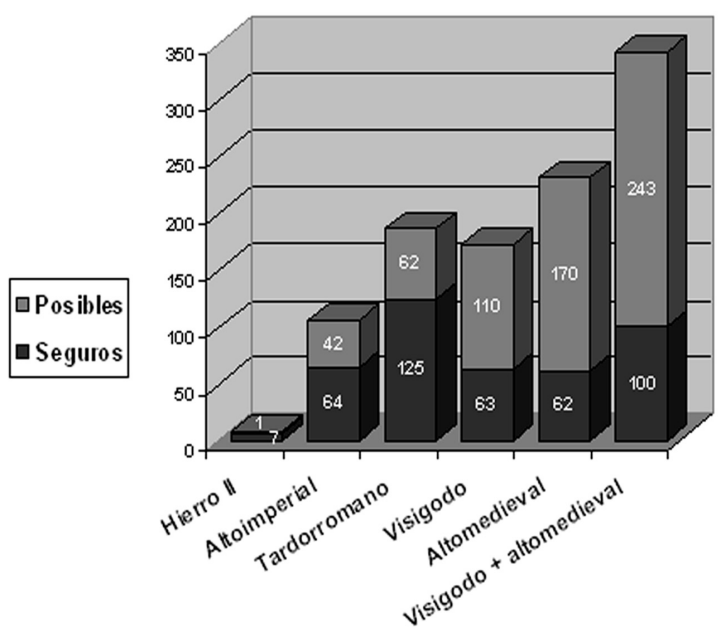

Figura 2. Histograma sobre la evolución del número de yacimientos arqueológicos por atribuciones crono-culturales, según datos del IACyL.

que evidencia unas estrategias de autosuficiencia, nula dispersión poblacional y débil integración política de las comunidades, se asiste a un claro fenómeno de colonización rural y promoción de pequeños pero activos centros urbanos desde época altoimperial.

En efecto, si apartamos de momento el problema que plantea la atribución cronológica del material de superficie post-romano, atisbamos una tendencia progresiva al aumento del número de sitios — tanto si consideramos los visigodos y altomedievales por separado, y por tanto consecutivos, como si los valoramos en un mismo bloque- que veremos consolidada en el poblamiento aldeano de época de repoblación, a mediados del siglo XII. A lo largo de los siguientes epígrafes iremos matizando esta tendencia general, que será relacionada con dinámicas concatenadas, como las de intensificación agraria, integración sociopolítica, extensión de los espacios productivos o concentración del hábitat.

En segundo lugar, el resumen gráfico de los datos compilados permite valorar la creciente extensión de la incertidumbre en las atribuciones crono-culturales, paralela a la escasez de fósiles-directores como referentes de los conjuntos cerámicos hallados en superficie.

\subsection{IMPLANTACIÓN DEL SISTEMA ROMANO EN ÉPOCA ALTOIMPERIAL}

En nuestro estudio partimos de reconocer una notable coherencia y homogeneidad en las estrategias de ocupación y uso del territorio vigentes durante 


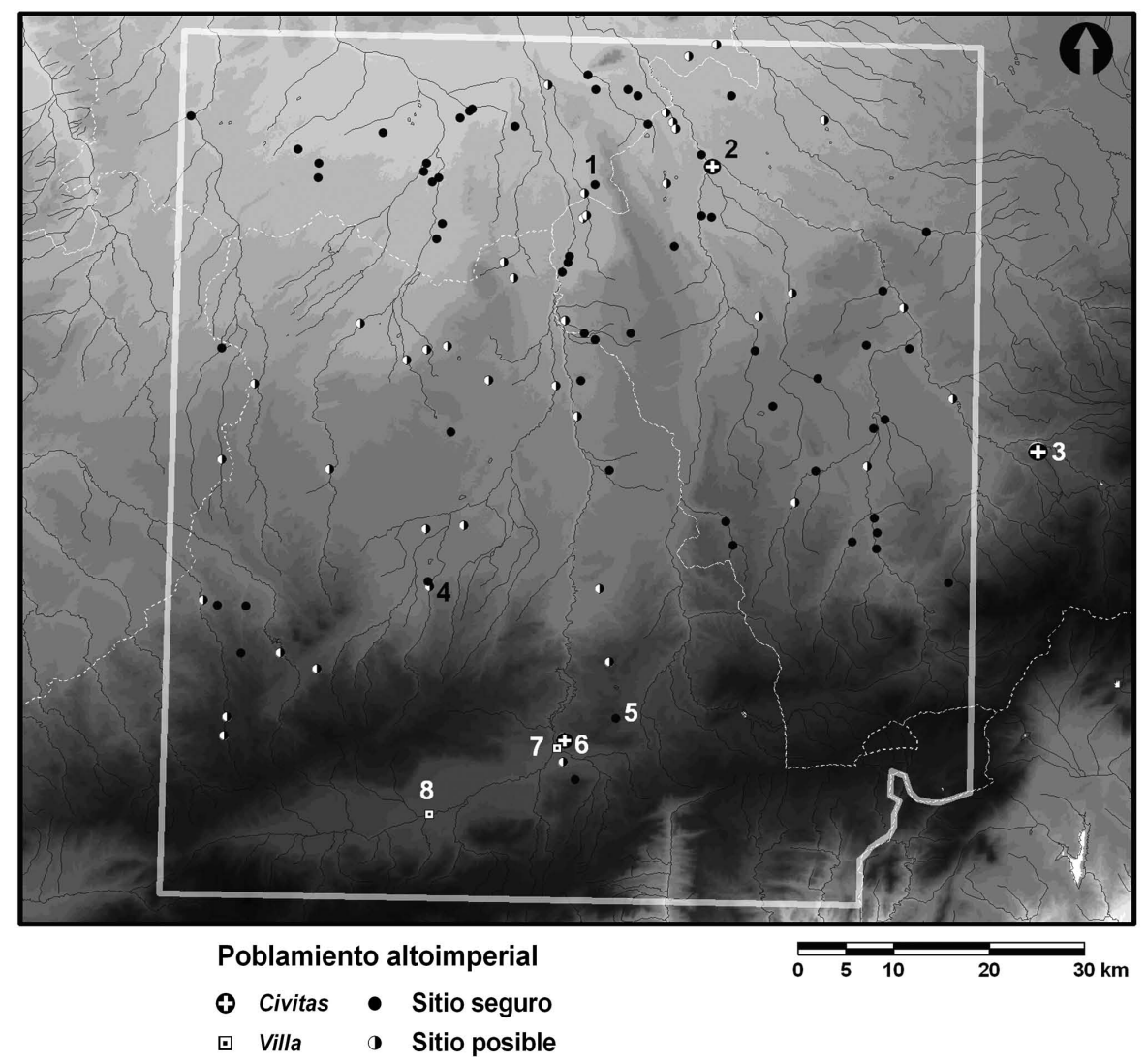

Figura 3. Ocupación del área de trabajo en época altoimperial. Sitios mencionados en el texto: 1. La Calzadilla (Almenara de Adaja); 2. Cauca (Coca); 3. Segovia; 4. El Vergel II (San Pedro del Arroyo); 5. La Laguna de los Casares (Ávila); 6. Avela (Ávila); 7. San Nicolás (Ávila); 8. La Pared de los Moros (Niharra).

toda la época imperial. Por tanto, aunque a efectos de análisis respetemos la distinción arqueológica entre una etapa altoimperial y otra tardía, en su interpretación histórica trataremos los datos obtenidos como pertenecientes a un sistema ordenado e interrelacionado, por encima de las normales diferencias de matiz.

La organización territorial prerromana supone un necesario contrapunto que permite apreciar el significado del impacto romano al sur del Duero. La ocupación por las comunidades de la Segunda Edad del Hierro del extenso territorio estudiado se efectuó a través de menos de una decena de sitios, de características homogéneas y política y funcionalmente autónomos. Se trata de aldeas de mediano y gran tamaño distantes entre sí, sobre relieves prominentes y bien delimitados - por la topografía y por obras artificiales de cierre-, exponentes de un alto grado de concentración poblacional. En el paisaje campiñés responden a este arquetipo los enclaves de Sieteiglesias
(Matapozuelos, Valladolid) (Bellido; Cruz 1993); Cauca y la Cuesta del Mercado (Coca Segovia) (Blanco García 1994; Pérez; Reyes 2007b), o el Cerro de la Virgen de Tormejón (Armuña, Segovia) (Blanco García 2006: 50-51); y ya en el Sistema Central los castros clásicos del Valle Ambles y sierras aledañas (Álvarez-Sanchís 1999: 115-164). Aunque a menudo se alude a la presencia de asentamientos subsidiarios en el llano como complemento de las aldeas fortificadas en alto (Ibidem: 117; Blanco García 2006: 41; Barrio Martín 1999: 166-167), lo cierto es que hasta el momento tales alquerías se resisten a ser detectadas, siendo un comportamiento, al parecer, exclusivo de esta época, pues no afecta a los yacimientos de cualquier otro momento. Cuando se han efectuado prospecciones intensivas, como en la comarca salmantina de La Armuña, tales asentamientos menores no aparecen (Ariño; Rodríguez 1997: 287; Ariño et al. 2002: 305). Cuando han sido mínimamente reconocidos (p.e. Blanco García 2006: 
43), los materiales que deparan — cerámica tardoceltibérica y de tradición indígena- cuadran mejor en el contexto de dominio político romano.

Por contra, los primeros indicios de ocupación de las campiñas en época romana caracterizan un asentamiento rural disperso, mediante núcleos de naturaleza muy heterogénea y funcionalmente complementarios. La imagen obtenida presenta grandes vacíos que han de explicarse por la desigual intensidad de las campañas de prospección (Fig. 3). En todo caso queda patente la efectiva ocupación y uso de amplias comarcas de alto valor agrario - tradicionales tierras de cerealicultura extensiva-, yermas de núcleos residenciales durante al menos los cuatro siglos previos. Este fenómeno de colonización fue impulsado por Roma, marcando una acusada discontinuidad con el poblamiento y las estrategias de subsistencia previas. Así, la ocupación del territorio en época altoimperial muestra caracteres propios y distintivos que responden a un esquema integral, abarcando diversos nichos ecológicos y una complementariedad de recursos entre las campiñas y las sierras.

A menudo se ha considerado que la presencia efectiva y la explotación del territorio al sur del Duero fue inestable y minoritaria hasta época tardo-romana (Mariné 1995: 290; Barraca 1998: 354). Conforme a lo que sabemos en otras regiones cercanas (Ariño et al. 2002: 287) el fenómeno que estamos describiendo, y que implicó la implantación del sistema vilicario en la región, se explica bien como el resultado de una colonización de datación inaugural flavia. Las excavaciones van precisando la relativa antigüedad de la puesta en funcionamiento de este sistema integral de explotación desde mediados del siglo I d.C, y ello a pesar del frecuente enmascaramiento de los restos julioclaudios y flavios debido a la monumentalización rural del siglo IV. En efecto, en las villae del siglo Iv es común reconocer una fase de ocupación altoimperial, si bien en muchas ocasiones resulta difícil caracterizar su naturaleza. Así ocurre, dentro de la zona de trabajo, en La Calzadilla (Almenara de Adaja) o en El Vergel II (San Pedro del Arroyo), donde las fases altoimperiales presentan restos mal conservados, y no puede asegurarse su identificación con villae (García Merino y Sánchez Simón 2001; Serrano 2007).

Sin embargo, otros testimonios son más explícitos y apuntan a que en ese momento funciona ya un entramado vilicario que vamos conociendo progresivamente. Así, entre las villae activas como centros agrarios y residencias aristocráticas desde ese momento cabe citar la suburbana de San Nicolás (Ávila), inmediata a la civitas de Avela (Quintana y Centeno 2006: 98), la villa de la Pared de los Moros (Niharra) (Martínez Pañarroya 2003), o las instalaciones residenciales no monumentales de La Laguna de los Casares (Ávila), tal vez la pars rustica de una villa (Strato 2001).

Esta temprana implantación y su consecuente dinámica de ocupación y explotación del territorio vendrían además avaladas por los datos paleoambientales, fundamentalmente de índole palinológica. El diagrama polínico de alta resolución obtenido en el Puerto de Serranillos, acotado por tres dataciones ${ }^{14} \mathrm{C}$ (López Sáez et al. 2009), indica la introducción del olivo hacia 100 cal AD en el Valle del Tiétar, al sur del área de estudio. Su importancia radica en testimoniar una explotación de rendimientos aplazados en plena zona serrana — considerada de más débil ocupación altoimperial- desde momentos antiguos. Parece claro pues el mencionado contraste a nivel regional respecto a la ocupación y explotación del territorio en época prerromana, lo cual se ha puesto en relación con un proceso de creciente intensificación económica (Martínez Caballero 2000: 19-23).

\subsection{LA ÉPOCA TARDO-ROMANA}

Esta etapa ha de considerarse como la prolongación y consolidación del sistema implantado desde época flavia, en un proceso que matiza la supuesta crisis de finales del siglo III en las tierras del interior (Chavarría 1994-1995: 189), que en todo caso se debe a cambios no estructurales. Así, el papel de las civitates en la zona de estudio, aunque modificado respecto a la fase altoimperial, sigue siendo relevante en el ámbito de la administración del territorio (Blanco García 1998; Pérez; Reyes 2007b). Estos núcleos urbanos, de relativamente escasa entidad monumental y poco claro papel en la articulación de un comercio local, seguirían siendo el referente territorial de la organización jurídico-política.

La ocupación del área estudiada en época tardoromana pone de manifiesto que se trata de un estadio avanzado del proceso iniciado unos siglos antes (Fig. 4). En estos momentos la unidad básica de ocupación y explotación parece ser la villa, si bien hoy no puede despreciarse el papel de otros establecimientos rurales dispersos, que funcionarían como unidades polifocales (Martín Viso; Barrios 2000-2001: 64-65; López Quiroga 2006: 32) o instalaciones secundarias de las propias villae, bien caracterizadas mediante prospección intensiva en zonas próximas 


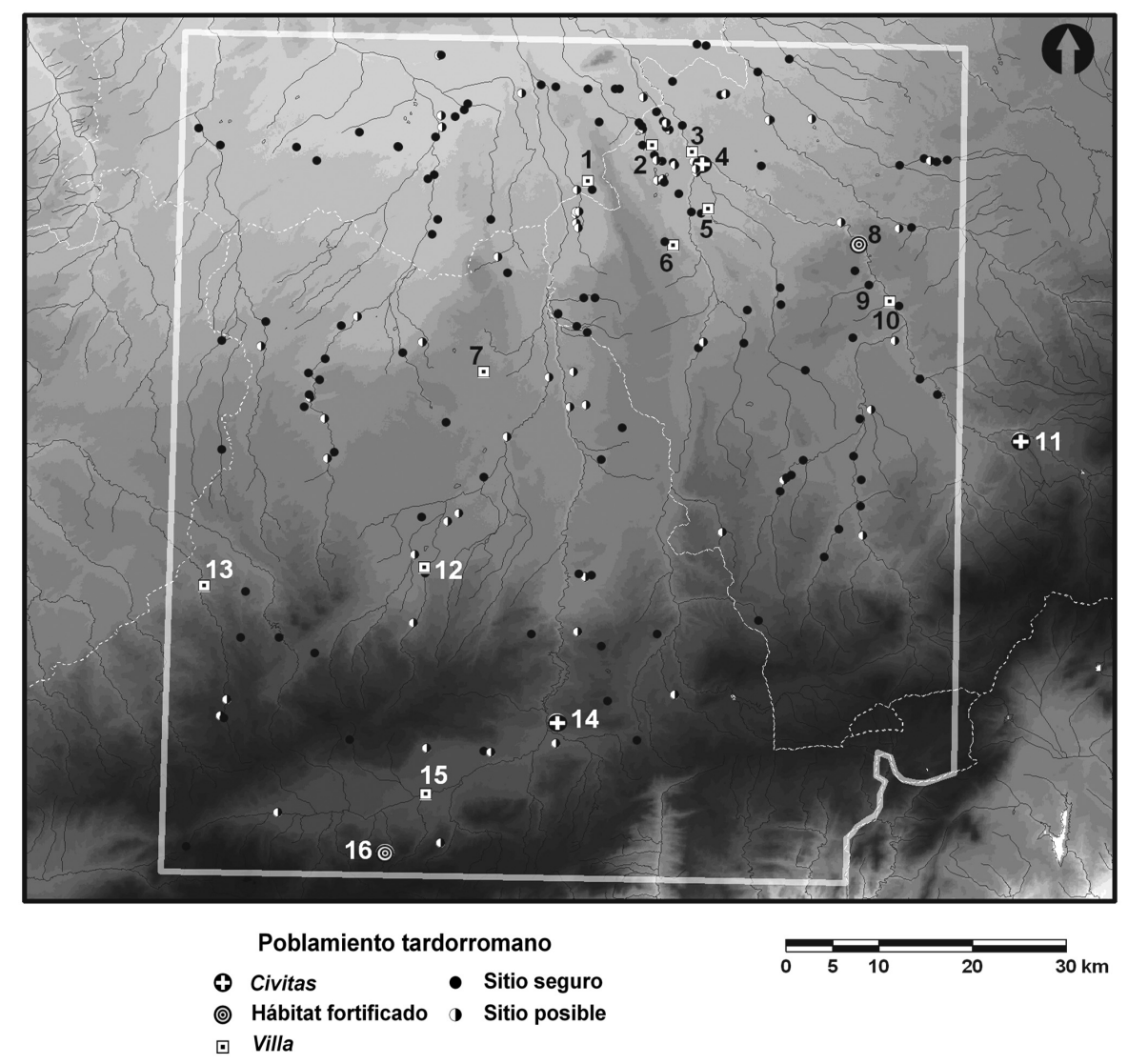

Figura 4. Ocupación tardorromana del área de trabajo. Sitios mencionados en el texto: 1. La Calzadilla (Almenara de Adaja); 2. Los Pozuelos (Villeguillo-Llano de Olmedo); 3. Las Pizarras (Coca); 4. Cauca (Coca); 5. El Pinar Nuevo (Coca); 6. Los Hornillos (Santiuste de San Juan Bautista); 7. El Torreón (Nava de Arévalo); 8. Cerro del Castillo (Bernardos); 9. Cerro de la Virgen de Tormejón (Armuña); 10. Los Casares (Armuña); 11. Segovia (Segovia); 12. El Vergel II (San Pedro del Arroyo); 13. La Claverona (Mancera de Arriba); 14. Abula (Ávila); 15. La Pared de los Moros (Niharra); 16. La Cabeza de Navasangil (Solosancho).

(Ariño et al. 2002: 289-291). Junto a ellos en la región de estudio asistimos al surgimiento de ciertos asentamientos en altura que prolongarán su vida en época visigoda.

A menudo se menciona la relativa abundancia y representatividad de los complejos vilicarios en la región (p.e. Mariné 1995: 315-317; Juan Tovar; Blanco García 1997: 173-174, fig. 1; Martínez Caballero 2000: 38-40; García Merino 2008). Aquí hemos empleado el restrictivo criterio de considerar como villae sólo aquellos ejemplos mejor documentados mediante excavación arqueológica o mediante fotografía aérea a baja altura, a sabiendas de que muchos más ejemplares sin confirmar pertenecerán a tal categoría. El mapa del poblamiento resultante (Fig. 4) permite avanzar algunas características de relieve.
Así, con los datos actuales, queda patente la generalización de los restos monumentales tardo-romanos, repartidos desigualmente por la zona de estudio. Se confirma por tanto la mayor densidad de las villae en las campiñas septentrionales, frente a unas manifestaciones más esporádicas - y que las excavaciones caracterizan como más modestas- conforme nos adentramos en el Sistema Central (TIR 1993; Mariné 1995: 315-317).

A nivel de las relaciones entre yacimientos, se aprecia la imbricación de los centros vilicarios en una malla de ocupación del territorio encabezada por las civitates, y en la que las villae parecen comportarse como focos de referencia para otros sitios menores, posiblemente instalaciones agrarias subsidiarias. 
Sobre la estructura interna y la organización arquitectónica de estos centros, hay que señalar que muestran la magnificencia de las aristocracias propietarias durante el siglo IV, cuando este tipo de infraestructuras rurales se convierten en efectivos centros de representación del poder (Chavarría 2006; García Merino 2008). Mencionaremos los ejemplos más destacados.

Entre las documentadas de antiguo y sin trabajos recientes destacan los hallazgos abulenses de mosaicos polícromos en La Claverona (Mancera de Arriba, Ávila) y la Torre Vieja o El Torreón (Magazos, Nava de Arévalo), esta última con restos escultóricos en mármol (Mariné 1995: 315-316). Algunas posibles villae periurbanas nos son conocidas a partir de restos de superficie en la periferia de Coca: Los Pozuelos, Los Hornillos y El Pinar Nuevo (Blanco García 1997: 389). Entre las mejor conocidas, por haberse beneficiado de sucesivas campañas de excavación, está la vallisoletana de La Calzadilla (Almenara de Adaja), en la que las recientes intervenciones entre 1998 y 2002 han permitido la total exhumación de la pars urbana, un complejo residencial de unos $2.500 \mathrm{~m}^{2}$ del siglo IV y en uso hasta fines del v, así como conocer las instalaciones, bastante arrasadas, de las partes fructuaria y rustica, y también un balneum (García Merino; Sánchez Simón 2001; ídem 2004). En el municipio segoviano de Coca, desde el año 2000 se viene excavando el complejo vilicario de Las Pizarras, que comprende tanto la pars urbana de una villa de peristilo como su pars frumentaria (Blanco García 1997: 380-383; Pérez; Reyes 2005 y 2007a). Destaca la variedad de solados musivos efectuados en diversos opera, que incluye técnicas mixtas —así lithostroton y opus sectile-. Existen diversas zonas funerarias tardoromanas y visigodas, especialmente visigodas en la pars rustica de la villa (Pérez; Reyes 2007b: 165170). Las excavaciones en el término municipal de San Pedro del Arroyo (Ávila) han permitido documentar una necrópolis tardía, posiblemente asociada a un centro cultual en el pago de El Vergel I. Por su parte, en el foco de El Vergel II los trabajos en curso $^{3}$ están exhumando más de $1.000 \mathrm{~m}^{2}$ de la pars urbana de una villa monumental vigente entre los siglos II y v, caracterizada por la exuberancia de la decoración musivaria polícroma de tres de los espacios documentados — con temas geométricos y figurativos como el mito de Meleagro y el jabalí de Calidón- y su reutilización funeraria en época visigoda

\footnotetext{
2008).
}

(Serrano 2007). La imponente villa de peristilo de Los Casares (Armuña) es conocida por fotografía aérea, mostrando una pars urbana de extraordinarias dimensiones, con aula biabsidada cruciforme, para la que se reivindica el patronazgo de un importante possessor, posiblemente de alto rango en la administración imperial teodosiana (Regueras; Olmo 1997). En fechas recientes ha sido objeto de algunas excavaciones de urgencia que parecen confirmar tales extremos (Gonzalo 2008: 624-25).

Por último, el esquema del poblamiento romano tardío se complementa con ciertos poblados amurallados, según la terminología de Abásolo (1999: 95). Algunos son apenas conocidos mediante prospección, como el Cerro de la Virgen de Tormejón (Armuña, Segovia) (Juan Tovar; Blanco García, 1997: 174 -75; Blanco García 2003: 156; Gonzalo 2007: 21). Otros asentamientos fortificados han sido ya objeto de excavaciones de envergadura y sus características comienzan a ser resaltadas. En La Cabeza de Navasangil (Solosancho) se documenta una primera fase de ocupación datada según sus excavadores (Caballero Arribas 2001; Fabián 2007: 105) entre finales del siglo Iv hasta su destrucción antes de comenzar el siglo vi. Algo posterior sería el momento fundacional del Cerro del Castillo (Bernardos), donde se han documentado algunas estructuras domésticas intramuros correspondientes a la fase más antigua, ubicada en la segunda mitad del siglo v (Fuentes; Barrios 1999; Gonzalo 2007: 34 y 35).

\section{3. ÉPOCA VISIGODA}

El estudio del poblamiento en época visigoda presenta como principal inconveniente la laxitud e imprecisión de las cronologías. No obstante, en regiones vecinas se ha conseguido una buena caracterización del poblamiento y la cultura material de este momento. En Salamanca ha sido posible combinando prospección intensiva con muestreo no selectivo del material de superficie en La Armuña (Ariño; Rodríguez 1997; Ariño et al. 2002) junto a fotografía aérea oblicua y excavaciones puntuales por la provincia, en contextos que abarcan toda la secuencia (Ariño 2006). Por su parte, en la campiña madrileña se ha asistido a una verdadera revolución del conocimiento sobre los enclaves visigodos tras la excavación en área de enormes superficies de ellos (Vigil-Escalera 2000, 2003a y 2006), integrando en el análisis una secuenciación de la cerámica común a partir de criterios tecnológicos (Vigil-Escalera 2003b). 


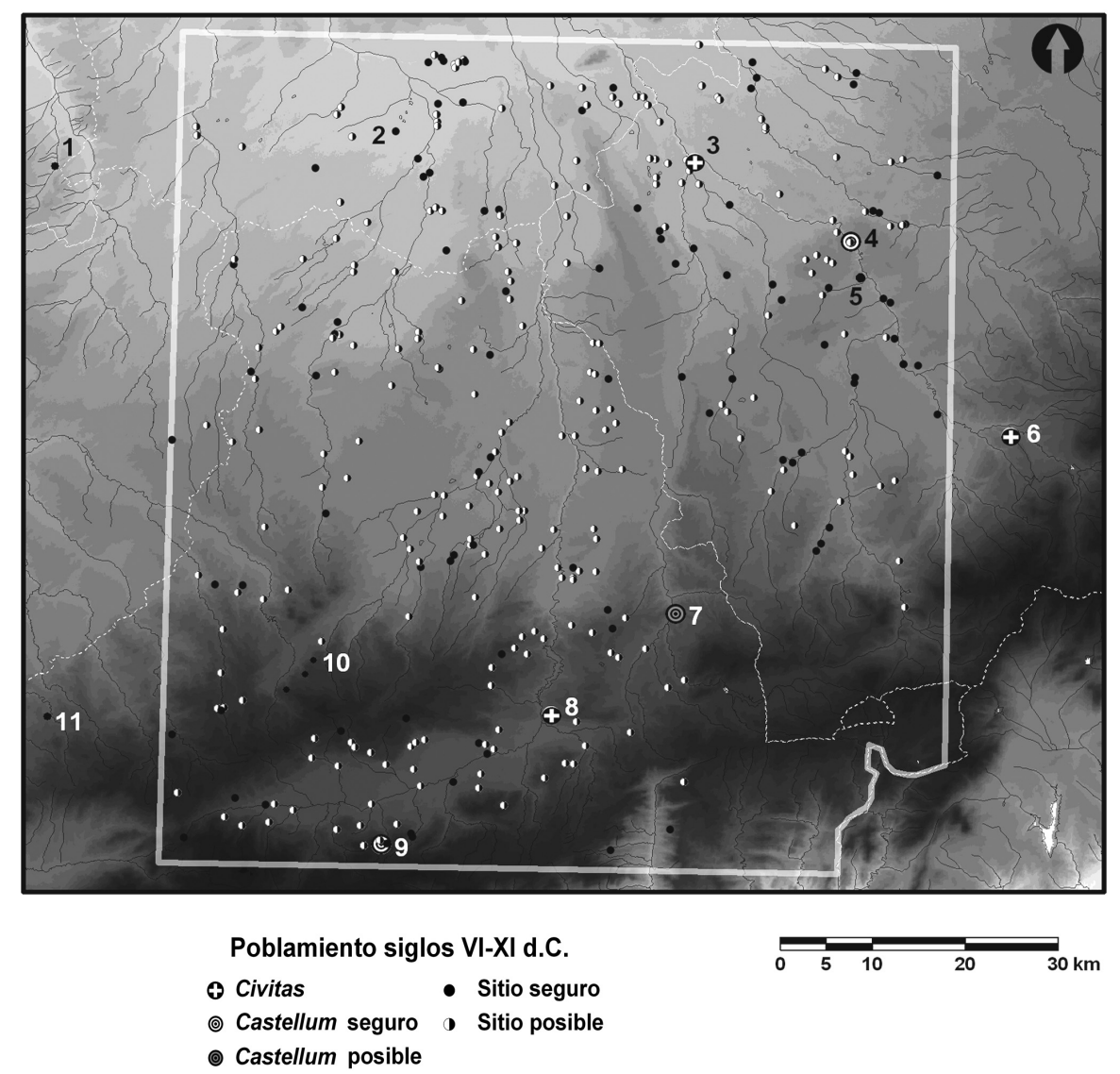

Figura 5. Ocupación de época visigoda y altomedieval (s. VI-XI d.C.). Sitios mencionados en el texto: 1. La Huesa (Cañizal); 2. El Pleito (Rubí de Bracamonte); 3. Cauca (Coca); 4. Brittablo (Cerro del Castillo, Bernardos); 5. Cerro de la Virgen de Tormejón (Armuña); 6. Segobia (Segovia); 7. San Juan (Ojos Albos); 8. Abula (Ávila); 9. La Cabeza de Navasangil (Solosancho); 10. Los Henrrenes (Cillán); 11. La Lancha del Trigo (Diego Álvaro).

Nuestra aproximación parte, como se ha explicado, de la información contenida en los inventarios arqueológicos de las provincias de Valladolid, Segovia, Salamanca y Ávila, obtenida por tanto mediante prospección extensiva o selectiva. Estas fuentes permiten disponer de un nutrido conjunto de sitios con las atribuciones crono-culturales de visigodo y altomedieval cristiano, que han de corresponder al complejo intervalo entre la desarticulación estatal romana en la segunda mitad del s. Iv y la ordenación feudal del territorio a finales del siglo XI. Se trata de un grupo de yacimientos, mal caracterizados y datados, que representan la ocupación del territorio comprendida entre la Antigüedad Tardía y los tiempos altomedievales (Fig. 5).

Como rasgos característicos del repertorio material que marca esta cronología se puede aludir a ciertas formas y decoraciones bien acotadas en las mencionadas regiones del interior peninsular (Ariño; Rodríguez 1997; Larrén et al. 2003; Vigil-Escalera 2003b; Ariño; Dahí 2008) dentro de unos repertorios dominados por alfarería común y de cocina. A partir de la revisión de las fichas de yacimientos del IACyL es de destacar la débil presencia de cerámicas de calidad o con decoraciones elaboradas en los sitios rurales ${ }^{4}$, frente a su mejor representación en los centros urbanos o en aquellos lugares de altura.

La imagen que ofrece este poblamiento post-romano responde a las densidades ya documentadas

\footnotetext{
4 Los lotes alfareros más significativos proceden de la excavación de extensas superficies, como ocurre en El Pleito (Rubí de Bracamonte, Valladolid) (Larrén et al. 2003: 287-288).
} 
dentro de la propia zona de trabajo y en regiones próximas. En efecto, la prospección intensiva de un transecto entre los ríos Adaja y Voltoya permitió registrar cierta proliferación de núcleos datados en este momento (Quirós; Vigil-Escalera 2006: 105 y 106, fig. 18). En cuanto al comportamiento en zonas vecinas, cabe destacar las imágenes obtenidas en la Armuña salmantina (Ariño et al. 2002: 290, fig. 5), en el sureste de la provincia de Valladolid (Calleja 2001: 127-128, fig. 1) o ya en la vertiente sur del Sistema Central, en la sierra de Guadarrama y la campiña meridional de Madrid (Vigil-Escalera 2006: 104, fig. 3; Quirós; Vigil-Escalera 2006: 85, fig. 3).

Tres notas parecen caracterizar los esquemas de ocupación y explotación del territorio en la zona tras la disolución del sistema romano: la discontinuidad física de los espacios residenciales respecto a los núcleos romanos - muy evidente en cuanto al abandono aristocrático del medio rural, convertido así en ámbito residencial campesino (Isla Frez 2001; Chavarría 2004-2005: 187)—; la posible continuidad en el uso de las infraestructuras agrarias, de la que sería buena prueba el establecimiento en torno a las instalaciones vilicarias romanas (Ariño et al. 2002: 306; Vigil-Escalera 2007: 250-251; Ariño 2007: 319) y una decidida proliferación del hábitat rural —frente al criterio de Blanco García (2003: 150)—, que responde ahora a una tipología heterogénea (López Quiroga 2006: 28-33; Vigil-Escalera 2006; Ariño 2007: 333).

En gran medida la ocupación del territorio en la zona de trabajo responde a tales pautas. Se asiste a la aparición de nuevos asentamientos rurales en llano (Guerra 2007: 167, fig. 8), en gran parte abiertos (Figs. 2 y 5), con una cultura material relativamente pobre y una escasa inversión en las infraestructuras. Pueden apreciarse diferencias regionales en su densidad, conformando agrupaciones lineales en torno a los principales ejes fluviales (Quirós; VigilEscalera 2006: 90-91 y 104). Si bien este incremento cuantitativo del hábitat rural frente a la época tardo-romana ha de relativizarse, debido al amplio lapso temporal que cubren las atribuciones visigoda y altomedieval —un intervalo de unos cinco siglos- su importancia cualitativa es manifiesta. En términos históricos supone el punto culminante de la tendencia de ocupación integral del territorio desencadenada desde la colonización altoimperial, y su visibilidad arqueológica contrasta vivamente con lo acontecido tras el siglo viII. Para algunos autores se trata sin duda de un sistema aldeano, fruto de procesos de ordenación política sobre amplios territorios (Quirós; Vigil-Escalera 2006; Vigil-Escalera 2006 y 2007).
En cuanto a la morfología interna de los sitios rurales, siguen características perfectamente documentadas en regiones colindantes (Vigil-Escalera 2000, 2003a; Ariño et al. 2002: 290-291) y confirmadas en las excavaciones de establecimientos campiñeses de cabañas rehundidas y hoyos, como los vallisoletanos El Pleito (Rubí de Bracamonte) (Larrén et al. 2003: 287-288) o ya al norte del río Duero, en Vega de Duero (Villabáñez) (Bellido Blanco 1997). Entre estos asentamientos cabría hablar tanto de instalaciones residenciales eventuales (Ariño 2006: 319) como de granjas y aldeas estables, según la tipología arqueológica propuesta por Vigil-Escalera $(2006 ; 2007)$. Tales sitios agrarios abiertos podrían responder a ciertas categorías de la documentación textual, como la de villulae (Isla Frez 2001: 19) o los loca mencionados en las pizarras inscritas coetáneas (Martín Viso 2007b: 181).

La densa malla de sitios rurales aparece salpicada de otros centros de mayor rango territorial (Fig. 5). Se trata de los asentamientos concentrados, civitates y castella, que parecen funcionar como núcleos residenciales de las aristocracias locales propietarias (Chavarría 2004-2005: 198-199; Vigil-Escalera 2006: 94) y desde donde se organizaría la explotación agraria y la recaudación de rentas (Martín Viso 2006, 2007b, 2008). Con seguridad la única civitas del territorio estudiado, convertida ahora en sede diocesana, es Abula (Balmaseda 2006: 237), pero si bien se cuestiona que Cauca alcanzara tal condición (Martín Viso 2007b: 280), se van conociendo suficientes indicios - algunos aún inéditos - como para no dudar de su carácter urbano ${ }^{5}$. En ambos sitios las excavaciones están permitiendo conocer detalles sobre su organización urbana, destacando los recientes hallazgos en la parte alta de Ávila (Centeno 2007; Fabián 2007) o la documentación de una vivienda con patio del s. vi en Coca (Pérez González; Reyes 2007b: 169-170).

Junto a las civitates, a cierta distancia de las mismas, encontramos núcleos concentrados rurales que responden a la tipología de castella o castra (Fig. 5), es decir, sitios en altura y fortificados. A juzgar por los contextos fundacionales — carentes de datacio-

\footnotetext{
5 El enclave caucense rondaba en época visigoda entre 13 y 15 ha de extensión; dispuso de al menos seis necrópolis a su alrededor (Cantosal, El Tinto, Sta. Rosalía, Cinco Caños, La Plaza y Las Pizarras), la primera de ellas organizada en calles (Blanco García 2002); de este núcleo procede una nutrida colección de pizarras de tipo Lerilla (unas 60, en gran parte inéditas); contó con instalaciones alfareras fijas (también inéditas) y la producción de cerámicas más importante de la zona segoviana. Estas informaciones nos han sido amablemente facilitadas por J. F. Blanco García.
} 
nes de radiocarbono y por tanto, abiertos a su discusión-, tales testimonios formarían parte del paisaje de fragmentación política del interior peninsular, todavía en época bajoimperial (Escalona 2006; Martín Viso 2008, e.p.). Sin embargo, se trata de un aspecto que futuros trabajos habrán de precisar. Por lo que sabemos hoy en día, algunos de ellos constituyen reocupaciones de castros prerromanos abandonados a mediados del s. I a.C., en la línea documentada en la vecina provincia de Salamanca (Ariño 2007: 331) como el Cerro de la Virgen de Tormejón (Armuña, Segovia) (Blanco García 2006: 50-51), y tal vez San Juan (Ojos Albos, Ávila). En otros sus fases de época visigoda suceden a niveles tardo-romanos y prolongan su vida hasta comienzos del s. viII, como en La Cabeza de Navasangil (Solosancho) (Caballero Arribas 2001; Fabián 2003: 277-278) o incluso hasta avanzado el siglo $\mathrm{x}$, como se ha propuesto en el Cerro del Castillo (Bernardos, Segovia) (Gonzalo 2007: 85). En efecto, se ha apuntado que dentro del espectro de sitios visigodos, serían precisamente los estructuralmente más complejos los que alcanzarían momentos más tardíos (Ariño 2006: 334). Pensamos que su relevante papel en los esquemas del poblamiento ha de explicar su vitalidad durante varios siglos. Las potestades atribuidas a tales centros de poder (Quirós; Vigil-Escalera 2006: 90), —donde sistemáticamente aparecen concentraciones de pizarras numerales- se ejercerían sobre sus circunscripciones territoriales, a través de una gradación jerárquica dentro de su común consideración como nodos para la ordenación del espacio campesino en el ámbito local (Martín Viso 2006: 277). Así, en nuestra zona (Fig. 5) es manifiesto el reparto político del territorio rural entre verdaderos núcleos urbanos - Abula y Segobia-, núcleos semiurbanos como Cauca, y una serie de sedes rurales intermedias - Cerro del Castillo (Bernardos), identificado por Martín Viso (ibidem: 280) con Brittablo, o la Cabeza de Navasangil-, ocasionalmente de naturaleza eclesiástica - como la Dehesa del Castillo (Diego Álvaro, Ávila)_ (ibidem: 280-282).

Todo ello habla a las claras de una ocupación densa, con una proliferación del hábitat rural — sobre cuya naturaleza apenas contamos en la zona con datos arqueológicos- y una explotación distinta del territorio, protagonizada por el campesinado.

\subsection{Poblamiento ENTRE LOS Siglos VIII-XI}

Tras la desarticulación del aparato estatal del regnum de Toledo y sus ramificaciones tributarias locales y hasta la integración política feudal de repoblación, la región constituye una tierra de nadie. Incluso en momentos tan avanzados como a finales del siglo IX los poderes en pugna en el escenario peninsular no afectaron sustancialmente a este sector. Las expediciones asturleonesas al sur del Duero, orientadas hacia el curso medio del Tormes y el valle del Duratón apenas significaron para nuestra zona la mera permanencia bajo el área de influencia cristiana. Las razias amiríes coetáneas tampoco la afectaron en su obtención de botín, pues se centraron en las mencionadas regiones, más pobladas y organizadas (Barrios 2000: 201-205).

Sin embargo la región no quedó yerma (Barrios 1983; Villar 1986; Zamora 1997) y a los mermados contingentes que permanecieron ha de atribuirse una cultura material y unas formas de asentamiento sólo reconocidos de manera incipiente. En este contexto el análisis del poblamiento altomedieval está adquiriendo tanto entre los medievalistas (p.e. Barrios; Martín Viso 2000-2001: 57) como entre los arqueólogos (Ariño et al. 2002: 303; Quirós; Vigil-Escalera 2006: 95) una importancia creciente. Si bien la idea que trasciende es la de ruptura en las pautas de ocupación del territorio frente al mundo visigodo (Ariño 2007: 334), las fórmulas adoptadas y los ritmos del proceso muestran un gran polimorfismo.

Así, en las campiñas septentrionales del área estudiada los sitios rurales ocupados durante los siglos VIII y IX son difícilmente distinguibles de los de época visigoda (Fig. 5). En el caso del sitio vallisoletano de El Pleito (Rubí de Bracamonte) la perduración en el siglo VIII es poco firme debido a la escasez de material cerámico (Larrén et al. 2003: 287 y 291). Por el contrario, en el zamorano de La Huesa (Cañizal) el lote documentado es muy expresivo (Presas et al. 1994; Nuño 2003: 184-193). Allí las cabañas rectangulares, rehundidas en el suelo y con zócalos de mampostería, se distribuyen a lo largo de una gran extensión, separadas por espacios yermos, y tal vez articuladas en torno a un edificio de culto (Larrén et al. 2003: 288; Nuño 2003: 141-142).

En la región meridional del área estudiada se comienzan a conocer los contextos arqueológicos de tal coyuntura, además de las frecuentes sepulturas rupestres, que han servido para rellenar los indicios sobre la ocupación del espacio entre el siglo IX y el XI (Zamora 1997: 420). En plena Sierra de Ávila se documentan pequeños asentamientos serranos (Fabián 2007: 107) de los que el mejor exponente es el despoblado abulense de Los Henrrenes o San Cristóbal (Cillán). Se trata de una aldea campesina parcialmente delimitada por una cerca pétrea — aspecto que de 
momento no ha de emplearse con valor cronológi$\mathrm{co}^{6}$ - que informa de cierta planificación del asentamiento. Recientes excavaciones en este enclave (Díaz de la Torre 2005) han documentado sencillas estructuras domésticas de planta rectangular, de en torno a $70 \mathrm{~m}^{2}$, similares a las halladas en 1958 en la Lancha del Trigo (Diego Álvaro, Ávila) (Gutiérrez Palacios et al. 1958) y que parecen traducir su ocupación por familias nucleares. Para ambos sitios, que traslucen una ocupación no muy dilatada - ausencia de superposición de suelos, escasa estratificaciónse ha propuesto una datación laxa, posterior al siglo VIII y previa a comienzos del XII (Díaz de la Torre 2005; Martín Viso 2006: 276).

Los problemas de la cerámica altomedieval en esta zona son acuciantes: ausencia de productos paleoandalusíes, monotonía y larga perduración de los tipos, ausencia de ornamento, predominio del repertorio común y de cocina (Ariño; Dahí 2008). Se requieren secuencias sobre repertorios de cerámica común obtenidos en lecturas estratigráficas, acotadas mediante el radiocarbono. Sin embargo, con la información disponible, tales enclaves rurales permiten algunas precisiones. Así, a partir del escueto lote alfarero recuperado en el serrano de Los Henrrenes (Díaz de la Torre 2005) y del más representativo campiñés de La Huesa (Nuño 2003: 170-180 y 186190), comprendidos entre el s. VII avanzado y el s. IX. Como notas distintivas se podría enarbolar el predominio de formas cerradas - especialmente cacharros de cocina-; el empleo exclusivo de fuegos reductores, una relativa recuperación del uso del torno rápido, la desaparición de la decoración estampillada o los rasgos de tradición clásica e, incluso, la presencia esporádica de los primeros bruñidos lineales verticales (Larrén et al. 2003: 304; Ariño; Dahí 2008).

Previsiblemente más claro resultará el panorama en aquellos centros que no respondan a una naturaleza agraria y rural, como los de carácter urbano - a pesar del actual desconocimiento al respecto ${ }^{7}$ o tal vez incluso militar, como se ha propuesto en el segoviano Cerro del Castillo (Bernardos), en cuya

6 Poblados delimitados con cercas se están datando entre el siglo vi, como el segoviano de la Cárcava de la Peladera (Hontoria) (Larrén et al. 2003: 281-283) hasta comienzos del VIII, como en el salmantino de La Legoriza (San Martín del Castañar) (Gómez Gandullo 2006).

7 En las excavaciones urbanas en Ávila los contextos arqueológicos de los siglos XI y x se resisten a aparecer (Fabián 2007: 86; Estremera 2006: 45), mientras que en Coca parece haber continuidad, si bien la información permanece inédita (Pérez; Reyes 2007b). Nada se sabe sobre el origen de los actuales pueblos, mencionados documentalmente a comienzos del s. XII. acrópolis pudo haberse establecido una guarnición, tal vez omeya, entre la segunda mitad del siglo vIII y mediados del siglo x (Gonzalo 2007: 97 y 105). Con independencia de tal hipótesis, sin duda polémica, por su volumen cabría clasificar este sitio entre el reducido número de plazas urbanas que consiguen eludir la generalizada ausencia de restos materiales andalusíes al norte del Sistema Central (Larrén et al. 2003: 277; Ariño; Dahí 2008). En efecto, allí la denominada cerámica común imitación de sigillata (Juan Tovar; Blanco García 1997) perdura hasta comienzos del vIII y es sustituida por un repertorio ajeno a la tradición local (Gonzalo 2007: 63-65). Se trata de cerámicas de cocción oxidante a torno rápido, con tonalidades claras y rojizas, superficies de tacto áspero y alguna pintura vinosa, que bien pudieran tildarse de andalusíes (ibidem: 81-90). Precisamente por la falta de dataciones absolutas, la amortización de ciertas pizarras visigodas en estructuras constructivas $^{8}$ ha llegado a convertirse en un referente post quem más para este horizonte (Martín Viso 2006: 276).

En definitiva, a partir del siglo vIII se asiste al desmantelamiento de la tupida red de ocupación y uso del sector vigente bajo dominio político visigodo, conforme a lo conocido en otras zonas del interior (Vigil-Escalera 2006, 2007; Ariño 2007). Tan sólo podemos mencionar la perduración de unos pocos sitios, desde los que tuvo que ejecutarse la explotación agraria de un territorio políticamente desarticulado. Si bien el papel de las ciudades nos es prácticamente desconocido, es previsible que adquirieran cierta relevancia en el cuadro de un poblamiento rural ralo. Por su parte, en el campo parece afianzarse un hábitat campesino, orientado a actividades agropastoriles de subsistencia, que podríamos calificar como concentrado en el Sistema Central - La Lancha del Trigo, Los Henrrenes- y más tendente a la dispersión en las campiñas al sur del Duero - La Huesa-.

Sobre estas infraestructuras agrarias y de poblamiento se instalarán desde finales del s. XI los contingentes repobladores, procediendo a una nueva ordenación jurídico-política que conllevó una dinamización de los procesos de intensificación agraria y concentración del hábitat.

${ }^{8}$ Así ocurre en el poblado abulense de la Lancha del Trigo (Diego Álvaro) (Gutiérrez Palacios et al. 1958: 78) o en las estructuras de época emiral del segoviano Cerro del Castillo (Bernardos) (Gonzalo 2007: 90-91), frente a su hallazgo en relación con contextos de uso en la Cabeza de Navasangil (Caballero Arribas 2001) y en la ciudad de Ávila (Centeno 2007: 129-130). 


\section{CONTRASTES EN EL USO DEL SUELO: EL VALLE AMBLÉS}

La necesidad de obtener informaciones alternativas sobre estos procesos de larga duración nos llevó a aproximarnos a los usos del suelo en el intervalo tratado. Se ha ensayado una evaluación cuantitativa de la accesibilidad desde los asentamientos a distintos tipo de terrenos clasificados según su capacidad agrológica. Para ello, se ha seleccionado una zona de estudio menor dentro del área de trabajo: el Valle Amblés, en el sector central de la provincia de Ávila (Fig. 6), por contar con un volumen manejable de sitios de atribución segura y cuyas informaciones han sido comprobadas. Se trata además de una zona perteneciente al Sistema Central, donde los contrastes entre el llano y la montaña resultan más acusados en distancias reducidas, lo que permite valorar suelos más variados que los que caracterizan las campiñas.

En este espacio de unos $1.650 \mathrm{~km}^{2}$ se ha aplicado una medición sistemática y uniforme de los tipos de suelos en el entorno de los yacimientos con datación segura comprendidos en las tres etapas mejor conocidas: altoimperial, tardorromana y visigoda. La escasez y precariedad de nuestros conocimientos sobre los sitios que prolongan su ocupación más allá del siglo VIII impide por el momento incluirlos en el análisis. El estudio de los territorios de explotación - site exploitation analysis - de tales sitios se ha
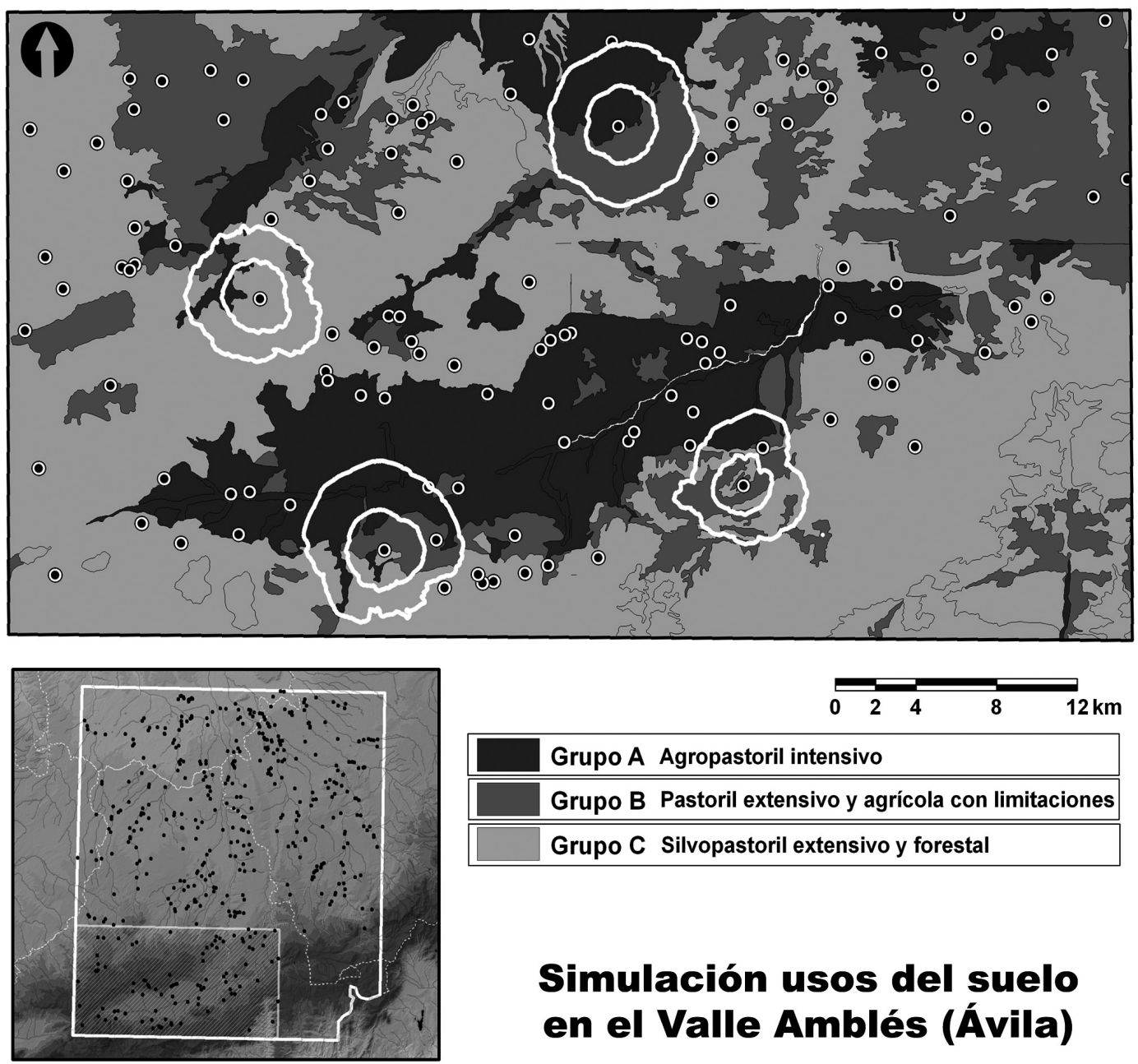

$8 \quad 12 \mathrm{~km}$

\begin{tabular}{|l|l|}
\hline & Grupo A Agropastoril intensivo \\
\hline \hline & Grupo B Pastoril extensivo y agrícola con limitaciones \\
\hline \hline & Grupo C Silvopastoril extensivo y forestal \\
\hline
\end{tabular}

\section{Simulación usos del suelo en el Valle Amblés (Ávila)}

Figura 6. Situación el área del Valle Amblés (Ávila) dentro de la zona de trabajo. Cartografía de calidad agrológica de los suelos con los yacimientos arqueológicos y ejemplos de los territorios de explotación de media hora y una hora generados mediante un SIG. 
empleado con una finalidad comparativa y no reconstructiva, como vía indirecta de observación de los usos del suelo ${ }^{9}$.

Hemos usado la rutina de un Sistema de Información Geográfica que, sobre un modelo de coste-distancia, permite dibujar los territorios de explotación como polígonos isócronos para, a continuación, medir con tales plantillas los tipos de suelos. El SIG ha simulado, pues los trechos recorridos a pie desde cada sitio estudiado en media hora y 1 hora de marcha y ha empleado tales halos para medir —en hectáreaslas superficies de las distintas categorías de suelos que contienen. Se ha utilizado la cartografía de Clases Agrológicas del Ministerio de Agricultura por usar un sistema cualitativo de clasificación basado en factores estructurales del suelo, sin mecanización ni aportes agroquímicos modernos.

Para facilitar la interpretación de los resultados, las seis clases agrológicas comprendidas se han agrupado en tres bloques de suelos homogéneos (Fig. 6) según sus usos tradicionales preferentes:

- Grupo A: Usos agropastoriles intensivos. Cultivos permanentes y pastos (Clases II+III). Terrenos planos más feraces, únicos que permiten una horticultura en zonas concretas, así como la cerealicultura de secano y un uso intensivo de las praderas para pastos.

- Grupo B: Usos pastoriles extensivos y agrícolas de secano con limitaciones (Clases IV+V). Admiten métodos de explotación no permanentes, con estrategias de descanso y bonificación.

- Grupo C: Usos silvopastoriles extensivos y forestales (Clases VI+VII). Suelos pedregosos y poco potentes de vocación pascícola, silvoforestal y cinegética.

Un estudio como el ensayado informa, pues, de la importancia relativa que pudo jugar la accesibilidad a determinados terrenos agrarios y forestales en la elección del asentamiento. Partimos de la premisa de que las comunidades campesinas estudiadas desarrollaron una perfecta integración de la agricultura y la ganadería, siguiendo estrategias de regeneración de nutrientes y descanso de los campos bien constatadas ya desde época prehistórica y que han dejado una importante huella tanto en la documentación medieval como en los usos del suelo tradicionales (Barrios 1983; Clément 2002: 61-62).

9 Los planteamientos teórico-metodológicos, sus problemas y limitaciones así como los detalles técnicos del estudio emprendido pueden consultarse en los trabajos de uno de nosotros (Blanco González 2008 y e.p.).
Los resultados para las tres etapas consideradas muestran una gran coherencia entre sí, lo que ha de explicarse como una notable continuidad en las pautas de ocupación del territorio, si bien se pueden resaltar algunos matices (Figs. 7 y 8 ).

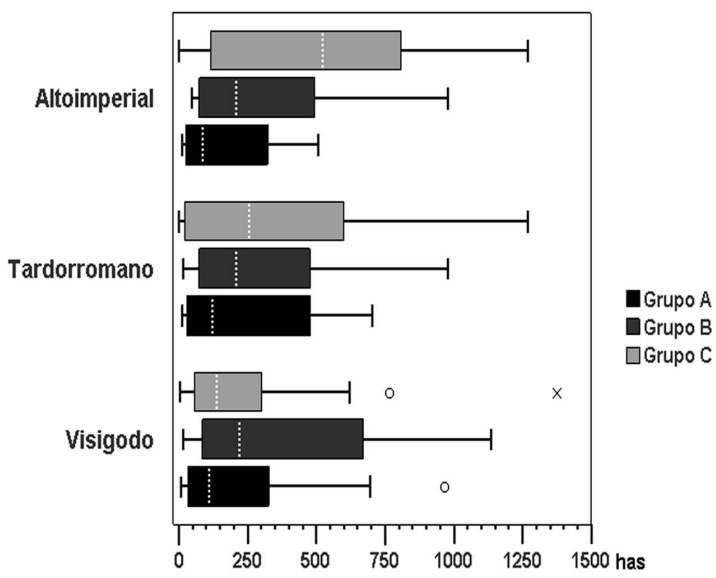

Figura 7. Gráficos de caja y arbotante comparando por épocas las superficies de suelos (en hectáreas) accesibles en 30 minutos desde los yacimientos. La línea de puntos blanca marca la mediana, y cada caja recoge el $50 \%$ de las mediciones. Los círculos señalan los valores atípicos, situados desde el umbral más próximo a una distancia entre 1,5 y 3 veces la dispersión central o longitud de la caja. Las «X» indican los casos aislados, más allá de ese punto.

En general, en el entorno inmediato a los asentamientos estudiados (Fig. 7) la proporción de las mejores tierras agrarias es muy similar a lo largo del tiempo, como muestra especialmente el valor de las medianas, en torno a las 100 ha. Las tierras del Grupo $\mathrm{B}$, de usos pastoriles extensivos y una agricultura con restricciones, resulta algo más importante en las tres etapas. Pensamos que su mayor representación en época visigoda puede relacionarse con la extensión del terrazgo agrícola hacia suelos de peor calidad, tal vez considerados marginales en época romana ${ }^{10}$. En el caso de las tierras de uso silvoforestal - Grupo Cqueda clara la progresiva tendencia diacrónica a reducir su importancia en las inmediaciones de los sitios.

En cuanto a las mediciones en el entorno a media distancia — una hora de marcha a pie desde los sitios- los resultados (Fig. 8) muestran una leve tendencia a la disponibilidad de mejores tierras

10 Una interpretación similar se ha planteado para la colonización del páramo leonés (Gutiérrez González 2008: 219 y 225-229). 


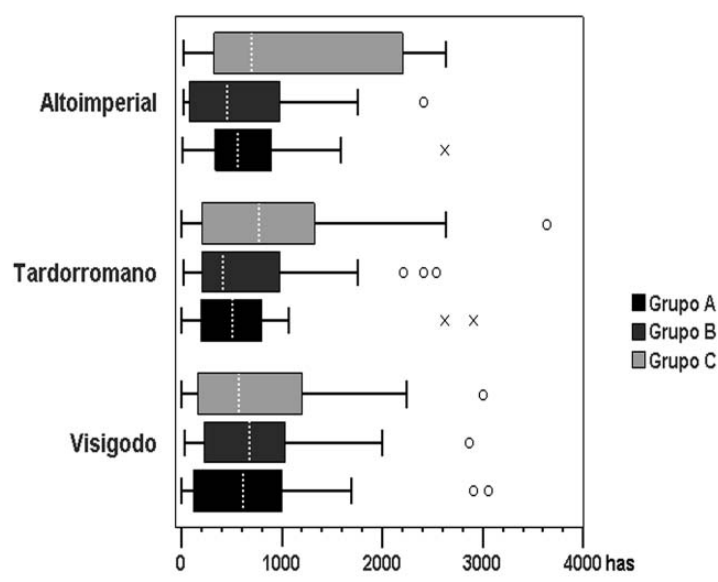

Figura 8. Gráficos de caja y arbotante con mediciones (en hectáreas) de los grupos de suelos accesibles en 1 hora desde los yacimientos. Los casos atípicos se simbolizan mediante círculos y los extremos mediante «X».

agrarias - Grupo A - en época visigoda y sobre todo confirma lo observado previamente: el decrecimiento en la disponibilidad de terrenos de uso no agrícola, que en época altoimperial parecen adquirir una notable presencia.

Dado el carácter experimental y no reconstructivo de la metodología empleada, estos resultados han de tomarse con cautela. En efecto, se trata de la exploración sobre una muestra de sitios que aunque consideramos representativa del panorama comarcal, es muy reducida ${ }^{11}$. En todo caso la distinción neta entre la etapa altoimperial y tardorromana resulta por el momento artificiosa, pues la propia reocupación de los sitios es muestra de la continuidad en las pautas de asentamiento y explotación del paisaje.

\section{DINÁMICA DE LOS PALEOPAISAJES}

Como complemento al estudio del poblamiento y los usos del suelo incluimos a continuación los resultados de varios estudios paleopalinológicos que informan directamente del intervalo temporal contemplado. Dos yacimientos romanos abulenses de reciente excavación han podido ser muestreados: El Vergel II y la Laguna de los Casares (Fig. 9), ofreciendo imágenes explícitas sobre el impacto antrópico en la zona del Sistema Central y en la transición hacia las

${ }^{11}$ Tras efectuar diversas pruebas con todos los yacimientos inventariados, finalmente el estudio de los territorios de explotación se ha efectuado sólo con los de cronología segura: 6 sitios altoimperiales, 16 tardorromanos y 13 visigodos. campiñas sedimentarias. Por otra parte, se ha estudiado una turbera inserta en plena zona de trabajo: la secuencia de Ojos Albos (Ávila), en el macizo del mismo nombre, que permite obtener una lectura diacrónica de la dinámica de las formaciones vegetales en los últimos dos milenios. La extrapolación de conclusiones generales a partir de registros puntuales es una preocupación implícita en cualquier estudio paleoambiental con un mínimo de rigor, y las advertencias sobre las limitaciones de tal enfoque (p.e. Lewit 2009: 78) se hacen extensivas a nuestro trabajo. Sin embargo, tendiendo muy presentes esas consideraciones, la mejor forma de ir perfilando nuestras carencias es abordarlas con estudios concretos, dirigidos a caracterizar esta oscura etapa. Por todo ello, ha resultado conveniente comparar estos registros polínicos con otros obtenidos en zonas colindantes al área de estudio, como es el caso del sondeo en la vega húmeda campiñesa del Prado de la Vega (Ariño et al. 2002) y el depósito de montaña del Puerto de Serranillos (López Sáez et al. 2009), que cuentan con dataciones absolutas y un registro de aceptable resolución. Por contra, los estudios realizados sobre depósitos del Valle Amblés (Andrade 1994; Andrade et al. 1994; Ruiz Zapata et al. 1996) apenas permiten afirmar algo, debido a la pérdida de detalle por su baja resolución muestral y una presen-

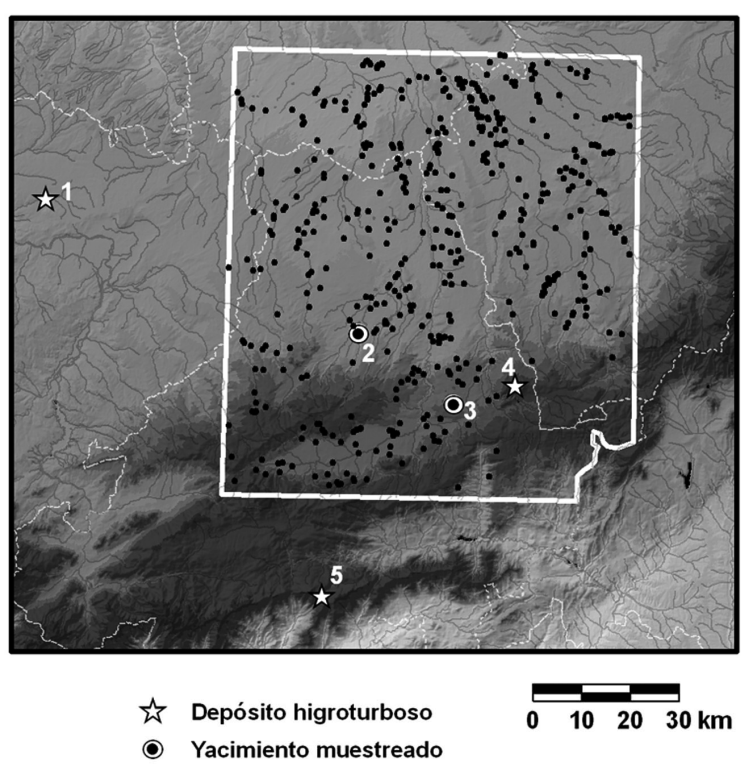

Figura 9. Zona de trabajo y registros arqueopalinológicos: 1. Sondeo del Prado de la Vega (Monterrubio de la Armuña, Salamanca); 2. Villa tardorromana de El Vergel II (San Pedro del Arroyo, Ávila); 3. Sitio altoimperial de la Laguna de los Casares (Ávila); 4. Turbera de Ojos Albos (Ávila); 5 Turbera del Puerto de Serranillos (San Esteban del Valle, Ávila). 
cia sólo esporádica de fechas de radiocarbono, que no ayudan a acotar los sedimentos correspondientes al tramo aquí estudiado.

4.1. Muestreos arqueopalinOlÓGicos EN yacimienTOS ARQUEOLÓGICOS

\section{Laguna de los Casares (Vicolozano, Ávila)}

Este sitio fue objeto de una campaña de excavación en extensión en 2001, que puso al descubierto los restos estructurales de un área residencial y posiblemente artesanal y productiva, datada entre los siglos I y II (Strato 2001). El análisis polínico (Fig. 10) se efectuó sobre dos muestras, procedentes respectivamente del núcleo 1 (cuadro 5, hoyo 1) y núcleo 4 (zona 2, nivel de ocupación). Ambas muestran una cobertura arbórea del orden del 33-37\%, donde sobresale la encina (19-21\%). De igual manera, elementos regionales como el melojo (3-4\%) y el pino albar (2-3\%) muestran también porcentajes testimoniales. En cambio, el fresno es abundante (5-6\%), seguramente como reflejo del entorno húmedo y lagunar en el que se sitúa este yacimiento. La cobertura arbustiva es igualmente escasa $(2-4 \%)$, siendo la jara pringosa (2-3\%) su elemento más significativo. Tal reducción de las formaciones forestales, sobre todo de aquéllas de carácter local como el encinar, abogarían por la deforestación del bosque climácico de la zona, el encinar. Esta hipótesis viene avalada por una considerable representación porcentual de la cobertura herbácea (59-65\%), en la cual son preponderantes los elementos correspondientes a los pastizales de vocación ganadera o antropozoógenos (47$51 \%$ ), así como la importancia del porcentaje de prados nitrófilos (33-42\%) combinado con el cultivo del cereal (3-5\%).

En conclusión, el estudio polínico de Laguna de Casares demuestra que el paisaje inmediato a este enclave agrario sufrió un impacto antrópico muy importante, centrándose primordialmente en la explotación pastoril del encinar y en el desarrollo en el entorno inmediato del yacimiento de cultivos de cereal. En paralelo a estos últimos, también se documenta el cultivo del olivo, pues polen de Olea europaea aparece con un 3-4\%. Relacionándose con todo lo anterior, la antropización del paisaje circundante al yacimiento fue importante, cobrando gran importancia los pastos nitrófilos como consecuencia de una intensa explotación agropastoril del territorio.

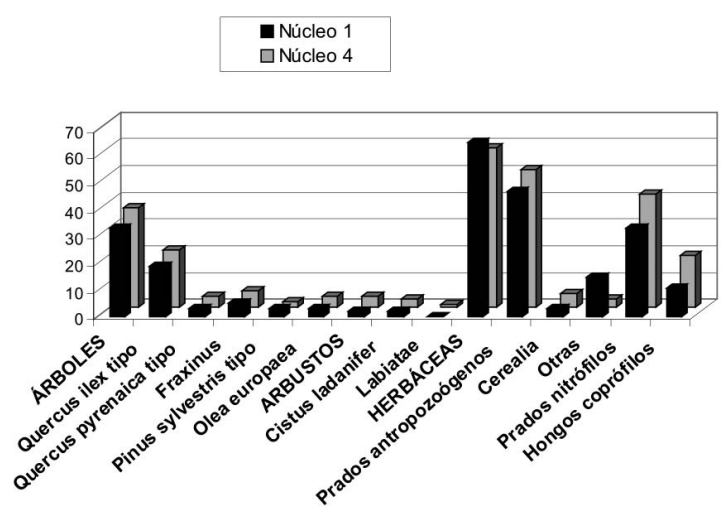

Figura 10: Histograma palinológico de la Laguna de los Casares (Vicolozano, Ávila).

\section{El Vergel II (San Pedro del Arroyo, Ávila)}

La villa de El Vergel, de cuyos hallazgos ya hemos hablado (Serrano 2007), también ha sido objeto de un estudio polínico (Fig. 11) a partir de otras dos muestras procedentes de las UUEE 118 (interior de ollita) y 175 (cenizal), es decir, de la ocupación del siglo IV. Los resultados muestran un paisaje relativamente forestado, con una cobertura arbórea más o menos densa (43-45\%), en la cual el elemento fundamental es la encina (Quercus ilex tipo) con un 23-25\%, y en menor medida el roble melojo (Quercus pyrenaica tipo, 9-10\%), el pino albar (Pinus sylvestris tipo, 6-8\%) y el fresno (Fraxinus, 3-4\%). La cobertura arbustiva es escasa (6-8\%) y apenas está constituida por jaras pringosas (Cistus ladanifer, 4$5 \%$ ) y diversas labiadas (2-3\%).

Estos datos apuntarían por tanto la existencia, en el entorno inmediato de la villa, de un encinar bien conservado y relativamente denso, aunque escaso en elementos arbustivos, posiblemente como reflejo de la presión pastoral que soportaría este bosque. De hecho, entre las herbáceas, que representan el 47$49 \%$, los principales elementos florísticos pertenecen a los prados antropozoógenos (30-37\%), de vocación ganadera y en los cuales prosperarían elementos como Plantago lanceolata tipo, Urtica dioica tipo o Chenopodiaceae-Amaranthaceae entre otros. Aludiendo a esta presión pastoral, sobre los encinares próximos a El Vergel, se documentan ascosporas fúngicas de hongos coprófilos (Sordaria y Sporormiella) con un 5-7\% (López Sáez et al. 1998, 2000). Lógicamente el porcentaje de éstos no es demasiado elevado dado que las muestras polínicas proceden del interior de la villa que no del exterior, donde hipotéticamente se situarían esos pastizales ganaderos ricos, sobre todo, en gramíneas. 
El porcentaje de roble melojo es relativamente bajo, lo mismo que el del pino albar, reflejando la procedencia regional de ambos: en el primer caso de los primeros contrafuertes montañosos del piso supramediterráneo en el entorno de las serranías gredenses; en el segundo, con seguridad, desde cotas altitudinales más elevadas en los pisos supramediterráneo superior y oromediterráneo de las cumbres de la Sierra de Gredos. En el caso del fresno, su porcentaje es igualmente bajo, lo cual podría aludir tanto a un impacto antrópico pastoril sobre la fresneda como a la especial ubicación de esta formación en las zonas riparias de la comarca.

Aunque el porcentaje de prados nitrófilos es del orden de un 13-19\%, éste tampoco es demasiado elevado dado el carácter zoófilo de los principales palinomorfos aquí incluidos (Cichorioideae, Cardueae, Aster tipo, etc), por lo que podría sostenerse que la buena conservación del encinar antes señalada vendría consentida por un impacto antrópico no demasiado elevado en el entorno inmediato, conservándose los bosques y su vegetación.

Por último, en ambas muestras ha podido identificarse polen de cereal, un $4 \%$ en la UE 118 y un $2 \%$ en la UE 175. Al menos para la primera, el porcentaje de cereal resulta suficiente para admitir la existencia de cultivos cerealísticos muy próximos a la villa (López Sáez; López Merino 2005).

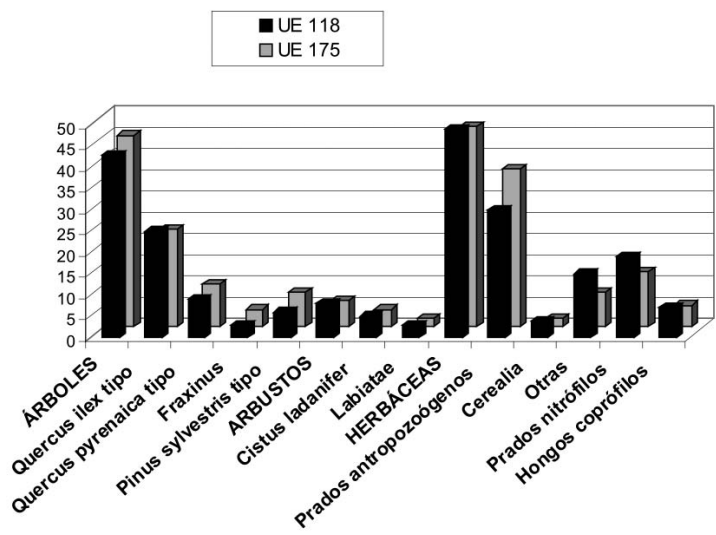

Figura 11: Histograma palinológico de El Vergel II (San Pedro del Arroyo, Ávila).

\subsection{La turbera de Ojos Albos y su Secuencia POLÍNICA}

La turbera de Ojos Albos se localiza en el seno de una vaguada de inundación en la cabecera del arroyo afluente del río Voltoya en la Sierra de Ojos Albos (Fig. 9). El estudio palinológico de este depó- sito higroturboso nos permite reconstruir la paleovegetación de dicha sierra desde al menos el siglo IV cal AD (Fig. 13), para lo cual nos hemos apoyado en la información aportada por 6 dataciones radiocarbónicas (Fig. 12). En la Fig. 13 se muestra una escala con la edad estimada en fechas calibradas cal AD, obtenida mediante un modelo edad-profundidad interpolando los ritmos de acumulación entre cada datación. Para realizar estas interpolaciones se han utilizado las dataciones calibradas en años cal AD a 2 ó, y dado que las calibraciones son intervalos de probabilidad, se ha escogido el punto de mayor probabilidad del intervalo de calibración para cada datación. Este punto de mayor probabilidad se ha obtenido con el programa de calibración CALIB 5.0.2, como referencia para los cálculos de las edades.

Entre los siglos IV y v cal AD, el paisaje de la Sierra de Ojos Albos parece dominado mayoritariamente por formaciones herbáceas, especialmente de gramíneas (Poaceae, ca. 40-50\%), siendo el porcentaje de palinomorfos arbóreos realmente escaso, entre los cuales deben destacarse, no obstante, la presencia de diversas especies de pinos (Pinus pinaster, Pinus pinea tipo, Pinus sylvestris tipo), todos ellos con carácter alóctono, ya que con toda seguridad no estaban presentes en nuestra área de estudio sino en zonas circundantes relativamente alejadas de la Sierra de Ojos Albos. Así, en el caso de los dos primeros pinos citados, probablemente provendrían de las zonas de fondo de valle de la Comarca de Pinares, al sur, donde actualmente prosperan densas formaciones mixtas de pinares piñoneros y resineros. En el caso de Pinus sylvestris tipo, tales palinomorfos, con toda seguridad, hacen referencia a la existencia de pinares altimontanos en las mayores cotas de las zonas montañosas aledañas, probablemente en Las Parameras e incluso en las zonas más occidentales de la Sierra de Guadarrama. Entre el resto de taxones arbóreos cabe sólo señalar una presencia testimonial de la encina (Quercus ilex tipo) y con mayor porcentaje del roble melojo (Quercus pyrenaica tipo, ca. $10 \%$ ). Con todo ello, el paleopaisaje de Ojos Albos en estos siglos mostraría un grado de deforestación muy alto, pues si eliminamos los diversos tipos de pinos, entre la flora arbórea apenas se detecta un $20 \%$ de robles y encinas. Entre la flora arbustiva, igualmente escasa, se han identificado las jaras (Cistus laurifolius tipo) y los brezos (Erica arborea tipo). Aparte de las gramíneas, antes nombradas, entre la flora herbácea cabe señalarse la identificación de un elenco de flora nitrófila reseñable (5-17\%), que indicarían una presión antrópica sobre el medio de esta sierra en tal marco cronológico. Otros palinomorfos 


\begin{tabular}{|c|c|c|c|}
\hline Número Lab $^{\mathbf{0}}$ & Muestra & Edad $^{14} \mathbf{C}$ & Edad Calibrada $^{\mathbf{C}}$ \\
\hline Ua-24765 & $26 \mathrm{~cm}$ & $101,7 \pm 0,5 \mathrm{pM}$ & $>1950 \mathrm{cal} . \mathrm{AD}$ \\
\hline Ua-24766 & $49-50 \mathrm{~cm}$ & $255 \pm 35 \mathrm{BP}$ & $1517-1948 \mathrm{cal} . \mathrm{AD}$ \\
\hline Ua-24767 & $69-70 \mathrm{~cm}$ & $955 \pm 40 \mathrm{BP}$ & $1000-1188 \mathrm{cal} . \mathrm{AD}$ \\
\hline Ua-24768 & $80 \mathrm{~cm}$ & $1280 \pm 40 \mathrm{BP}$ & $600-863 \mathrm{cal} . \mathrm{AD}$ \\
\hline Ua-24769 & $100-101 \mathrm{~cm}$ & $1555 \pm 40 \mathrm{BP}$ & $423-600 \mathrm{cal} . \mathrm{AD}$ \\
\hline Ua-24770 & $117 \mathrm{~cm}$ & $1720 \pm 40 \mathrm{BP}$ & $240-416 \mathrm{cal} . \mathrm{AD}$ \\
\hline
\end{tabular}

Figura 12.: Dataciones radiocarbónicas de la turbera de Ojos Albos (Ávila) y su edad calibrada a $2 \sigma$.

herbáceos, de naturaleza antropozoógena $(<10 \%)$ indicarían cierto tipo de presión pastoral, en todo caso residual o esporádica. Se ha identificado polen de cereal aunque en porcentajes bajos $(<3 \%)$, lo que no nos permite confirmar su cultivo local pero sí en las inmediaciones próximas, posiblemente en el fondo de valle anexo (López Sáez; López Merino 2005).

La presencia de polen de olivo (Olea europaea) es constante en este intervalo temporal (siglos IV-V cal AD), aunque con valores que no superan el $1 \%$, y que únicamente supondrían una procedencia extra-regional del taxón desde zonas alejadas al área estudiada, donde probablemente se cultivaba gracias a la benignidad climática del periodo cálido romano que duraría aproximadamente hasta mediados del siglo v cal AD (Desprat et al. 2003). Estos datos coinciden con los aportados por el estudio palinológico de la turbera del Puerto de Serranillos (López Sáez et al. 2009) que igualmente demuestran el cultivo del olivo en tales fechas.

En cambio, el centeno (Secale cereale) empezó a ser cultivado en Ojos Albos sólo hacia el siglo v $\mathrm{AD}$, en paralelo a la ralentización del cultivo del olivo y cierto retroceso del robledal, posiblemente en relación con la primera influencia de un periodo de marcado detrimento climático, el llamado periodo frío altomedieval, que se extendería desde la segunda mitad del siglo v cal AD hasta la segunda mitad del siglo x cal AD (Desprat et al. 2003).

Entre los siglos VI y XVIII cal AD la paleovegetación apenas difiere sensiblemente de los siglos precedentes con presencia alóctona, a veces importante, de diversas especies de pino (sobre todo en el siglo XIV cal AD), con presencia local mínima de melojares en la Sierra de Ojos Albos y de encinares en sus cotas más bajas, así como de todo un elenco de flora nitrófila o antropozoógena que darían cuenta de procesos de antropización del paisaje de esta sierra, mayoritariamente mediados por la presencia de ga- nado en su entorno. Al igual que antes, se sigue documentando polen de cereal pero en porcentajes bajos, redundando en su carácter extra-local, posiblemente a partir de aportes de las zonas de valle inmediatas. Estos hechos parecen confirmar que la Sierra de Ojos Albos ha sido siempre, predominantemente, una zona ganadera, y con toda probabilidad en las épocas estivales. De hecho, en este marco cronológico, siguen siendo abundantes los pastos antropozoógenos (más importantes que en los siglos IV-V cal AD), pero sobre todo se produce un aumento espectacular de los hongos coprófilos que nos indicarían la presencia de ganado in situ (López Sáez et al. 2000).

Dentro de este amplio marco cronológico de los siglos VI a XVIII cal AD, el diagrama polínico permite percibir periodos de mayor cambio en la paleovegetación y gestión del territorio de la Sierra de Ojos Albos, que a continuación se describen.

Entre los siglos x y XIII cal AD se produce un aumento muy significativo de las quercíneas caducifolias, del roble melojo, coincidente con una mayor proliferación de la maquía termófila de jaras y brezos, momento que además conlleva un mayor grado de antropización de la sierra y con la mayor presencia del cereal, así como con un máximo muy importante de los pastos húmedos. Todo esto nos haría pensar en unas condiciones más benignas a nivel climático, de tipo templado-húmedas, que se corresponderían con el denominado periodo cálido bajomedieval, y en paralelo con el hecho de que la repoblación de la zona se iniciara hacia el año 1087 d.C. Este periodo también se ha confirmado en el Puerto de Serranillos (López Sáez et al. 2009), y a lo largo de él los cereales y el centeno se cultivan entre los siglos X-XII cal AD, posteriormente se abandonan y se recupera el cultivo del olivo a partir del siglo XIII cal AD.

Dentro del intervalo de los siglos X-XIII cal AD, hay un momento en el que se rompe la dinámica antes 


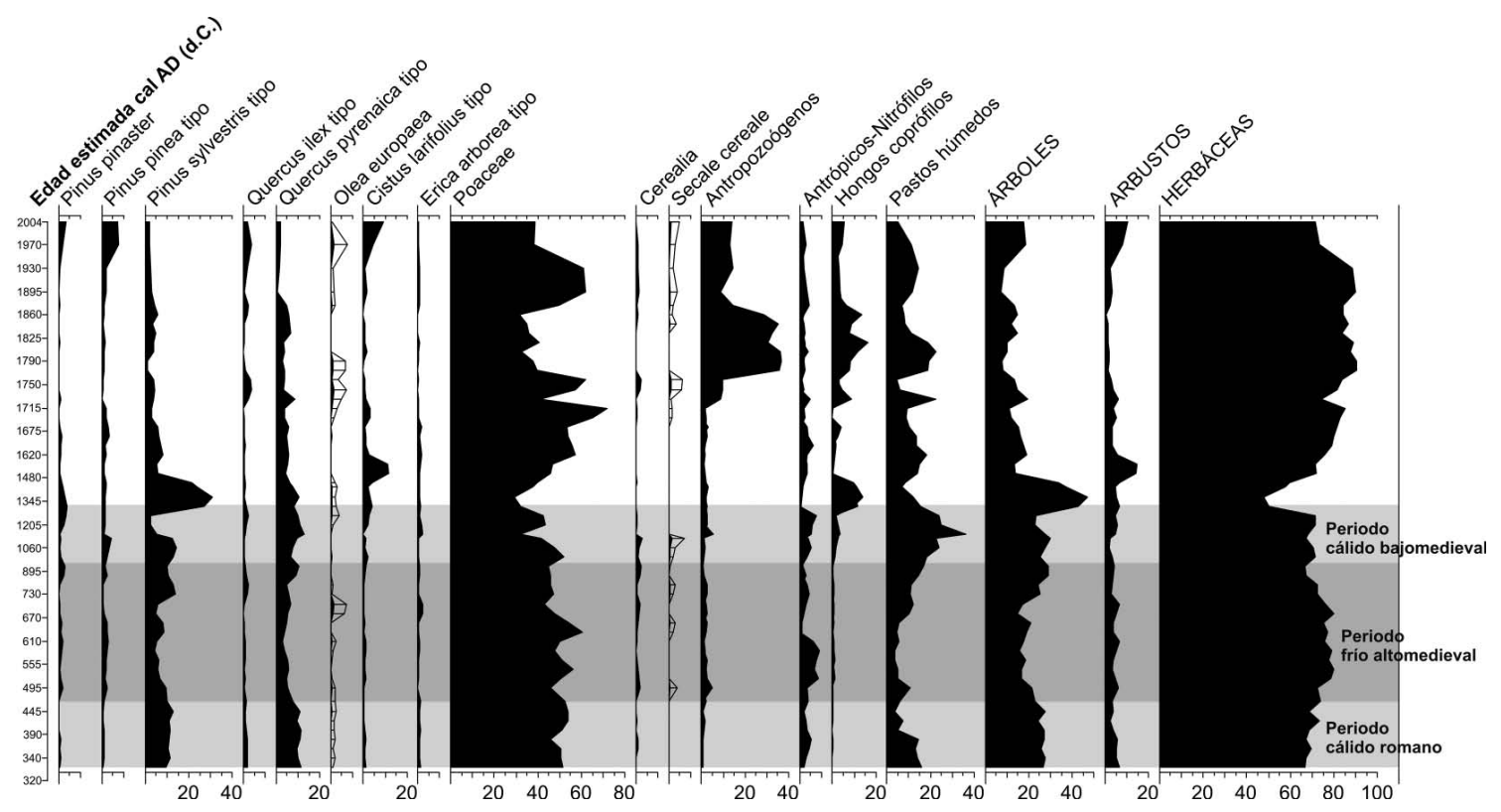

Figura 13. Diagrama palinológico sintético de la secuencia de Ojos Albos (Ávila).

expuesta, justo en la transición entre los siglos XIIXIII cal AD, en el cual el pinar de Pinus sylvestris sufre un retroceso muy importante bajando del 5\%, coincidiendo con la progresión del jaral de Cistus laurifolius, el completo cese — como vimos- del cultivo de diversos cereales incluyendo el centeno y, también, cierto retroceso en la presión pastoral. Es probable que estos hechos tengan alguna vinculación con un periodo más árido, pues de hecho los pastos húmedos se reducen sensiblemente, así como con un cambio sustancial en la gestión de estos territorios, pues justo a continuación, como se dijo, se recupera el cultivo del olivo y la presión pastoral se hace muy importante a partir del siglo XIII cal AD.

Durante los siglos XIV y XV cal AD, el diagrama polínico muestra máximos de todos los indicadores de actividades ganaderas, tanto de los pastos antropozoógenos como ante todo de los hongos coprófilos. Todo ello coincide, a su vez, con una disminución importante de los pastos húmedos de Cyperaceae y de los pastos graminoides. En este mismo marco cronológico, el pino albar (Pinus sylvestris tipo) aumenta considerablemente $(>30 \%)$ y desaparecen casi todos los indicadores de antropización de los pastizales antrópico-nitrófilos. Estos datos nos hacen pensar en una fase seca importante, lo cual redundaría en la progresiva desaparición de los pastos húmedos, facilitando así la llegada de la cabaña ganadera al seno mismo de la turbera, y al aumentar la presión sobre los pastos locales desaparecería la mayor par- te de las gramíneas. De igual forma, este marco temporal coincidiría quizá con la mayor presión pastoral de la sierra derivada del trasiego de los ganados mesteños bajomedievales, para los cuales Ojos Albos fue una vía de paso importante.

\section{SÍNTESIS}

A partir de las informaciones presentadas, queda claro que todo intento de interpretación global del intervalo y la zona en estudio adolecerá de la ausencia de precisión en las cronologías y de falta de una caracterización más detallada de muchos aspectos, apenas esbozados. Sin embargo, la integración de las informaciones reunidas permite plantear un marco explicativo preliminar. Aunque los ritmos concretos de los diversos procesos interrelacionados en examen nos son sólo parcialmente conocidos, se intuyen ya dinámicas discontinuas de dispersión y agrupación del hábitat, de extensión y reducción del espacio agrario, de intensificación agraria o de permanencia y eventualidad del hábitat rural. La lectura en el tiempo largo (longue durée) permite resaltar así ciertas referencias nítidas del proceso histórico.

El punto de arranque coincide con el fuerte impacto de la colonización romana, que implicó la sustitución de las estrategias del Hierro II —de débil integración política, autosuficiencia productiva y absoluta concentración del hábitat en aldeas fortificadas- por 
otras nuevas. Su implantación habría acaecido en época altoimperial, antes de lo admitido por algunos autores. El deforestado entorno registrado mediante el polen en el yacimiento de la Laguna de Los Casares hacia el siglo II, en un medio geográfico de mediana calidad agraria y donde es desconocida la ocupación del Hierro II, refleja un alto impacto antrópico, explicable como el efecto de varias generaciones de prácticas agroforestales de cierta intensidad. La implantación de este sistema romano respondería a un fenómeno de colonización de espacios de alto potencial agrario, como las campiñas, y abarcaría una notable diversificación productiva. Así parece mostrarlo la temprana ocupación de los distintos nichos ecológicos del área estudiada. No puede descartarse cierta especialización productiva, como, de estar en lo cierto, podría indicar la preponderancia de las tierras de uso no agrícola - Grupo C - en el entorno de los sitios altoimperiales del Valle Amblés.

En época tardor-omana documentamos las consecuencias de varios siglos de funcionamiento del sistema romano: la ocupación del territorio alcanza a configurar una nutrida red de asentamientos agrarios dispersos, que giran en torno a las villae. Algunos establecimientos amurallados en altura completan un esquema territorial complejo, dirigido probablemente a la intensificación de la producción agraria. Los complejos vilicarios del siglo IV funcionan como pujantes residencias aristocráticas y dinámicos centros de producción agraria, según muestran los resultados polínicos en la villa abulense de El Vergel II. Las estrategias de ocupación del territorio priman los entornos campiñeses, donde la densidad de villae es mayor que en el Sistema Central (Fig. 4). La explotación agropastoril de las llanuras sedimentarias parece pues un rasgo relevante entre los regímenes de tenencia y gestión agraria de las grandes propiedades fundiarias. Estos dominios aristocráticos —que en casos como el de la villa segoviana de Los Casares pudieron pertenecer a individuos de alto rango administrativo en época teodosiana- estarían formados por heredades de mediana y gran extensión caracterizadas por su dispersión geográfica. Tal vez por ello el estudio mediante SIG de los suelos en los entornos más cercanos a los sitios tardorromanos del Valle Amblés apenas nos ha permitido caracterizar leves tendencias, en una línea marcada por la continuidad de las estrategias productivas. Aun así, los enclaves en tal dominio serrano tienden a situarse en terrenos de potencialidad agraria más equilibrada aún, con un leve repunte de la disponibilidad de tierras óptimas para usos agropastoriles permanentes —Grupo A- (Fig. 7).
Todo apunta, por tanto, hacia unos procesos de intensificación agraria a lo largo del sistema romano, dirigidos desde núcleos de poder rural en los que no faltan ciertos hitos territoriales - como los poblados amurallados - complementarios de las villae y las urbes. En un estadio avanzado, hacia el s. v, la turbera de Ojos Albos acusa una mermada cubierta forestal, con melojares y encinares en retroceso, y la extensión en ese medio serrano de los pastizales antropozoógenos (Fig. 13). El intercambio de productos agrarios como factor dinamizador de la especialización productiva pudiera quedar avalado por el cultivo del olivo, que aparece bien constatado en estos momentos, tanto en El Vergel II como en Ojos Albos.

No tenemos suficiente resolución cronológica como para enlazar el sistema romano con la coyuntura que sobrevino tras el desplome de la estructura imperial (p.e. Quirós; Vigil-Escalera 2006: 86-90). En efecto, nuestro enfoque en el tiempo largo tiende a realzar los efectos acumulativos, consumados, de la ordenación y uso del territorio sobre el territorio analizado. Así, alcanzamos a definir el poblamiento vigente en un momento avanzado del regnum toledano como probable resultado de un ejercicio de promoción política tendente a una ocupación integral del territorio (Fig. 5), pero desde una lógica de apropiación del mismo muy distinta. Además se conformó una malla rural aún más nutrida, implicando el interés por espacios productivos antes considerados marginales, mejor adaptados a estrategias extensivas y diversificadas según micro-regiones (Lewit 2009: 79-82). Tal red de humildes asentamientos campesinos parece adecuarse a una eficaz organización del territorio, que probablemente conllevaría su control desde un conjunto jerarquizado de centros en altura.

Tanto el estudio de los usos del suelo en el Valle Amblés a partir de tales sitios, como las secuencias polínicas diacrónicas coinciden en señalar cierta estabilidad de las estrategias productivas respecto al panorama precedente, tal como se constata en otras regiones europeas entre los siglos v y vi (ibidem: 79). En concreto, en época visigoda los usos del suelo simulados mediante SIG en este valle intramontañoso muestran unas proporciones de clases de terrenos muy equilibradas, que no permiten confirmar una posible tendencia ganadera y forestal en relación directa con el tipo de poblamiento elegido, como previsiblemente indicaría un incremento en los valores de suelos del Grupo C. Es decir, que la presunta deriva hacia un régimen de ganadería extensiva pudo haberse emprendido sin que afectara a la localización del asentamiento. 
En cambio, del estudio de los usos potenciales del suelo junto al hábitat rural visigodo sí es posible advertir la importancia relativa que adquirieron los terrenos de calidad agraria intermedia o Grupo B (Fig. 7). El beneficio de estos suelos requiere unas prácticas agroganaderas diversificadas e integradas, y una serie de técnicas de regeneración de nutrientes —abonado, cultivo al tercio, empleo de leguminosas para nitrogenar las parcelas, etc. - y costosas infraestructuras agrarias, como bancales para corregir la pendiente o zanjas de drenaje para evitar el anegamiento; todos ellos requisitos materiales bien constatados entre comunidades coetáneas (Quirós y Vigil-Escalera: 109-110; Vigil-Escalera 2006, idem 2007: 272-273). Además el cultivo del centeno (Secale cereale) que según el diagrama polínico de Ojos Albos se emprende en estos momentos (Fig. 13), pudo haber jugado un importante papel, en consonancia con su auge en la Europa altomedieval (p.e. Behre 1992: 149-152; Hamerow 2002: 135-137; Lewit 2009: 81). En efecto, se trata de un cereal más resistente que el trigo, mejor adaptado a las exigencias de una posible ampliación del terrazgo agrícola: en ecotonos de mayor altitud soporta las heladas, precisa de relativamente menor aporte hídrico y prospera en suelos de mediana calidad.

En definitiva, los campesinos de época visigoda estarían en condiciones de apropiarse y sacar buen partido del uso agrario de esta clase de terrenos, ganados al bosque mediante su roturación. La capacidad de aprovechamiento agrario de los suelos del Grupo B sería pues un requisito necesario para apoyar la hipótesis de la colonización y aprovechamiento de nuevos espacios agroforestales, como se ha propuesto para el Valle Amblés (Blanco González e.p.), dentro de estrategias de diversificación productiva propias de comunidades campesinas. Esta serie de anotaciones no constituyen sin embargo una explicación del fenómeno: en último término la decisión de ampliar el terrazgo partiría de unos concretos condicionantes sociales, políticos y demográficos.

Junto a la importancia de la cerealicultura de secano y de ciertos productos de huerta en zonas irrigadas - que han quedado bien documentados en época romana-, cabe resaltar ahora la importancia de la arboricultura mediterránea. En efecto, desde este momento tanto el olivo como la vid —ésta última peor representada en los espectros obtenidos, pues su carácter zoófilo limita la dispersión polínica - alcanzan un gran papel. El interés de estos cultivos radica en su probable destino comercial (Quirós; VigilEscalera 2006: 109), pues si bien se insertaría dentro de limitados circuitos intercomarcales, se trata de una actividad claramente excedentaria. En la zona bajo estudio no se han detectado aún estructuras de esta época relacionadas con la producción oleícola y vinaria, como las conocidas en su entorno (Ariño et al. 2004-2005; Vigil-Escalera 2006: 106, fig. 7; Ariño 2007: 326-328). Sin embargo el polen de olivo (Olea europaea) se detecta ya hacia 100 cal AD en la turbera del Puerto de Serranillos (López-Sáez et al. 2009) y en Ojos Albos comparece desde el comienzo de la secuencia. Por el bajo porcentaje en época romana no podemos admitir su cultivo local en la sierra, aunque sí en un ámbito extra-regional. Significativamente el olivo se mantiene estable durante los siglos v y VI, alcanzando su máximo valor en el palinograma entre los siglos VII-VIII cal AD (Fig. 13), momento en que puede afirmarse su cultivo comarcalmente, al menos en las zonas más bajas de la Sierra de Ojos Albos (Fig. 13).

Otro aspecto de importancia en la historiografía actual, ya aludido, ha sido la búsqueda y explicación de cambios en las pautas agroganaderas en época visigoda. En el registro de Ojos Albos, sobre todo desde el vi en adelante, se asiste a un importante incremento de los taxones antrópico-nitrófilos: tanto los pastos antropozoógenos como los hongos coprófilos están presentes de una manera constante y con porcentajes cada vez más importantes. Podemos relacionar este hecho con una presión humana y pastoril mucho más intensa en estas zonas de montaña. Fenómenos como éste ya han sido advertidos en otras regiones, y se han relacionado con el desarrollo de unas estrategias extensivas, que favorecerían la dedicación ganadera a costa de la actividad agrícola (Ariño et al. 2002: 308; Chavarría 2004-2005: 198199; Gutiérrez González 2008: 219). Interpretación esta última no exenta de detractores (Hamerow 2002: 112; Quirós; Vigil-Escalera 2006: 83) que no consideran válidos tales argumentos para afirmar una preponderancia ganadera.

Con los datos presentados aquí no apreciamos una merma significativa de la actividad agrícola, ni en los usos del suelo cerca del hábitat ni en las secuencias polínicas. En cambio sí constatamos reiteradamente fenómenos asociados al clareo del bosque y la extensión de los pastos en época visigoda. Al respecto, se ha dudado de la existencia real de una deforestación a partir del siglo $\mathrm{V}$ tras comparar el alto porcentaje de polen arbóreo (AP) en los entornos de un conjunto de sitios visigodos frente a otros tardorromanos, también muestreados (Quirós; Vigil-Escalera 2006: 109110). Pensamos que este tipo de contrastes, sobre muestreos polínicos en sedimentos arqueológicos, son idóneos para estudiar los ámbitos agrarios —que tan 
bien reflejan la cerealicultura y la actividad ganadera en pastos de cercanía-, mientras que su interpretación en términos de las dinámicas de antropización de ámbito regional resulta más problemática. Como alternativa hemos recurrido a sondeos polínicos diacrónicos, de alta resolución muestral y acotación temporal mediante radiocarbono, efectuados sobre depósitos naturales de montaña. A partir de los registros de que disponemos, hemos verificado la tendencia a una progresiva deforestación en los entornos boscosos serranos, aquellos no directamente relacionados con los ámbitos de residencia y presencia permanente de la población. En efecto, es allí donde se manifiesta en estos momentos la presión humana sobre las masas forestales altimontanas $(\mathrm{Pi}$ nus sylvestris y/o $P$. nigra) y sobre los melojares a media altura. La recesión en los valores regionales de AP obtenidos en la turbera de Ojos Albos parece indicar una intensificación de las cortas forestales a partir de mediados del v — para madera o leña- y la introducción del ganado, deducida del aumento de las herbáceas y los elementos antrópicos-nitrófilos (Fig. 13). Eventos semejantes se documentan en el Puerto de Serranillos (López Sáez et al. 2009), donde en época visigoda se produce una profunda deforestación del pinar altimontano, provocando el desarrollo de matorrales degradativos de estos bosques.

Las dificultades para reconocer formas de hábitat rural en las serranías (Fig. 5) nos hace plantearnos que el fenómeno probablemente respondería a campañas de trabajo ganadero y forestal estacionales. Se retrotraerían por tanto hasta estos momentos unas prácticas tradicionales de cooperación comunitaria de las que disponemos de numerosos testimonios ${ }^{12}$.

Por otra parte, a la vista de los registros polínicos cabe argumentar que el impacto ecológico sobre las masas forestales fue muy importante. Al respecto no contamos con indicios claros sobre la práctica de rozas con fuego, pero este tipo de usos no son en absoluto descartables, como parecen apuntar algunos testimonios. Así, en el yacimiento salmantino de Los Melgares (La Vellés), en las campiñas de la Armuña, en una reciente excavación preventiva se ha detectado un extenso depósito ceniciento de arrastre, datado en época visigoda, que se ha relacionado con el empleo de rozas para clarear el bosque, unido a consiguientes fenómenos erosivos (Ariño; Dahí 2008).

${ }^{12}$ En tal sentido resulta significativa la presencia, cerca de la turbera sondeada por nosotros, de sitios serranos como El Castillejo-El Castrejón (Ojos Albos), un posible recinto ganadero, bien conservado y de difícil datación por la ausencia de material asociado. Agradecemos la información a Francisco Fabián.
Es más, aparte del efecto combinado del impacto antrópico y de la cabaña ganadera, estas dinámicas de deforestación del bosque se verían agudizadas por la concurrencia del cambio hacia un clima más frío y seco; el periodo frío altomedieval ca. 450950 cal AD. Este cambio climático, bien registrado en otras regiones europeas (p.e. Cheyette 2008: $157 \mathrm{ss}$ ), ha podido ser acotado en la secuencia polínica de Ojos Albos y en depósitos higroturbosos cercanos, como la zona VEG-F del Prado de la Vega (Ariño et al. 2002: 297) o el Puerto de Serranillos (López Sáez et al. 2009) y supuso el descenso de las temperaturas y un régimen pluviométrico inestable, con sequías severas (Desprat et al. 2003: 72-73). Tal vez un reflejo indirecto de esta degradación climática pudiera verse en los cambios del propio patrón de asentamiento (p.e. Cheyette 2008: 162-163). En efecto, aun con las reservas que nos plantea la escasa resolución cronológica de los datos de superficie, parece desprenderse un establecimiento en virtud de zonas húmedas que en época romana probablemente quedarían anegadas. Se trata de localizaciones no ya estrechamente asociadas a la red fluvial — siguiendo una tendencia secular-, sino en entornos incluso eventualmente encharcados de esas vegas y riberas (p.e. Ariño 2007: 335) o inmediatas a humedales - los bodones o lavajos - en las campiñas al sur del Duero (p.e. Calleja 2001: 126), que en el Valle Amblés se traduce en la ocupación de zonas de topografía deprimida, como la misma plataforma de inundación del río Adaja (Fig. 5).

A partir del siglo viII el cambio es patente a todos los niveles. Parece claro que las transformaciones responden a un contexto de desarticulación política y económica (Castellanos; Martín Viso 2005), si bien falta una contrastación arqueológica de las propuestas interpretativas generales apuntadas para el interior peninsular (p.e. Martín Viso 2007a: 34-35; Vigil-Escalera 2006: 97). En las extremaduras del Duero parece asistirse a fenómenos de diversificación regional (Martín Viso e.p.) como ya hemos apuntado. Entre los rasgos ubicuos destaca la tendencia a una mayor eventualidad del hábitat, que tan bien contrasta con el modelo tardoantiguo de la villa señorial (Ariño 2007: 335). Las soluciones que adopta el asentamiento no están claras: una opción parece consistir en la reunión de unidades familiares dentro de un concepto cercano al de las comunidades de aldea — probables casos de Los Henrrenes (Díaz de la Torre 2005) o la Lancha del Trigo (Gutiérrez Palacios et al. 1958)_; mientras que otras fórmulas pudieran indicar una agregación laxa de ocupaciones domésticas, como el enclave zamorano de La Huesa (Nuño 2003). 
En cuanto a las pautas de subsistencia, poco puede asegurarse con certeza, si bien cabe un replanteamiento de la dinámica expansiva altomedieval a partir de las trayectorias precedentes, que poco a poco van siendo mejor conocidas (Vigil-Escalera 2009: 218219). Tras desarticularse los flujos de intercambio entre comarcas y diluirse la presión de los aristócratas locales, el espectro de opciones pudo ser amplio, dentro de una básica orientación hacia la autosuficiencia. De nuevo encontramos propuestas sobre la diversificación productiva de las comunidades, y sobre todo se enfatiza la especialización ganadera que pudieron adoptar tales grupos. Ya en las primeras investigaciones sistemáticas y documentadas sobre la región, como la de Barrios (1983: 122), se pronosticaba una especial dedicación ganadera entre los grupos que permanecieron hasta época de repoblación. Tal estrategia respondería a la inestabilidad política, las adversidades climáticas y la ocupación de suelos pobres serranos, que daría lugar a un paisaje caracterizado por el predominio del saltus sobre el ager. Los datos disponibles no permiten desmentir esa imagen, aunque sí matizarla, reivindicando cierta continuidad de las actividades agroforestales. Así, en Ojos Albos el taxón Cerealia marca la perduración de la cerealicultura de secano hasta el siglo XII y algo similar cabe decir respecto al cultivo del centeno (Fig. 13). En cuanto a las masas forestales - especialmente pinares y melojares-, cabe señalar su eventual recuperación entre 850 y 950 cal $\mathrm{AD}$, posible reflejo de la merma demográfica, que conllevó la recesión del impacto sobre el bosque. Esta regeneración de las formaciones boscosas es también patente en las campiñas meridionales del Duero, como muestra la zona VEG-E del sondeo de La Armuña (Ariño et al. 2002: 300).

Respecto al clima cabe señalar que durante esta etapa se asiste al Periodo Cálido Medieval (ca. 9501400 cal AD) caracterizado por un aumento de la pluviosidad y las temperaturas, que haría más agradable la ocupación de entornos serranos como los elegidos por los poblados abulenses de la Lancha del Trigo o Los Henrrenes.

Por último, el proceso repoblador desde finales del siglo XI implicó el aprovechamiento y potenciación de las estructuras agrarias y de poblamiento preexistentes en la zona. La ordenación feudal del territorio estudiado probablemente conllevó la consolidación y promoción de gran parte de los procesos de larga duración mantenidos de manera fluctuante durante siglos. De esta forma, habría que revalorizar la larga historia agraria del sector y el protagonismo del componente campesino autóctono. Ello conlleva re- formular el significado histórico de los paisajes agrarios feudales en su justa medida, en el contexto de largos procesos en los que cuadran mal las ideas sobre unos medios naturales prístinos (Barrios 1983, 2000).

A modo de colofón de cuanto venimos señalando, entre los procesos implicados en la organización plenomedieval del territorio cabría destacar la concentración del poblamiento, que queda reducido definitivamente y hasta nuestros días a las aldeas y villas urbanas. En sintonía asistimos a la proliferación del hábitat rural — debido a un despegue demográfico hacia 1200 sin precedentes-, de la que da sobrada muestra la extensa red aldeana documentada hacia mediados del XIII en las extremaduras (Barrios 1984: 14-23; Villar 1986). Entre los aspectos productivos, se asiste a un momento álgido de la intensificación agraria: la roturación y ampliación del terrazgo a una escala desconocida, así como la extensión de la cabaña ganadera, o del cultivo de la vid y el olivo. Se trata ya sin duda de actividades especializadas, insertas en una economía de mercado y un sistema de percepción de rentas dinamizado por las aristocracias feudales (Barrios 1983: 155; Villar 1986: 135-153). Estas dinámicas han quedado bien reflejadas en la turbera de Ojos Albos (Fig. 13), con una cadencia progresiva sólo interrumpida por algunos posibles eventos cortos de cambio climático, como el acaecido entre los siglos XII-XIII cal AD. Igualmente se rastrean en el Puerto de Serranillos (López Sáez et al. 2009) y en el sondeo polínico del Prado de la Vega —zona VEG-D_ donde la intensificación de la actividad pastoril se ha relacionado con la formación del paisaje adehesado (Ariño et al. 2002: 300-301).

En definitiva, a lo largo del texto se han apuntado algunos elementos legibles y reiteradamente constatados en las formas de ocupación y uso del territorio, que servirán para articular hipótesis de trabajo sobre las bases materiales del proceso histórico en el primer milenio d.C. La investigación futura en la región presenta el reto de verificar el grado de desarrollo que alcanzaron algunos de esos vectores infraestructurales entre la Antigüedad y el Medievo, así como esclarecer los factores históricos que explicarían las dinámicas aquí apenas esbozadas.

\section{AGRADECIMIENTOS}

Los autores quieren reconocer la ayuda y facilidades que en la obtención de los datos del IACyL y en la consulta de las fichas de yacimientos y las memorias de excavación nos han dispensado Milagros Burón, Francisco Fabián y Jorge Santiago. La 
versión preliminar del trabajo se ha beneficiado de los comentarios, referencias bibliográficas e informaciones de Alfonso Vigil-Escalera, Juan Francisco Blanco García, Iñaki Martín Viso, Santiago Castellanos y Enrique Ariño. Del texto final y las opiniones vertidas en él somos los únicos responsables.

\section{BIBLIOGRAFÍA}

Abásolo, J. A. 1999, «La ciudad romana en la Meseta Norte durante la Antigüedad tardía», L. García Moreno; S. Rascón (eds.), Complutum y las ciudades hispanas en la antigüedad tardía. Alcalá de Henares, 87-99.

Andrade, A. 1994, Dinámica de la vegetación durante los últimos 3000 años en las Sierras de la Paramera, Serrota y Villafranca (Ávila) a partir del análisis polínico, Tesis Doctoral. Universidad de Alcalá de Henares.

Andrade, A.; Dorado, M.; Ruiz-Zapata, B. 1994, «Estudio comparativo de la evolución de la vegetación a partir del tránsito Subboreal-Subatlántico en las sierras abulenses (Ávila, Sistema Central, España)», I. Mateu; M. Dupré; J. Güelmes; M.E. Burgaz (eds.): Trabajos de Palinología básica y aplicada, Actas del $X^{o}$ Simposio de Palinología, (A.P.L.E.), 199-210.

Ariño Gil, E. 2006, «Modelos de poblamiento rural en la provincia de Salamanca (España) entre la Antigüedad y la Alta Edad Media», Zephyrus LIX, 317-337.

Ariño Gil, E.; Rodríguez Hernández, J. 1997, «El poblamiento romano y visigodo en el territorio de Salamanca: Datos de una prospección intensiva», Zephyrus L, 225-245.

Ariño Gil, E.; Rodríguez Hernández, J.; Riera, S. 2002, «De Roma al medievo: estructuras de hábitat y evolución del paisaje vegetal en el territorio de Salamanca, Zephyrus LV, 283-309

Ariño Gil, E.; Barbero, L.; Díaz Martínez, P.C. 20042005, «El yacimimento agrícola de El Cuquero y el modelo de poblamiento en época visigoda en el valle del río Alagón (Salamanca, España)», Lancia 6, 205-231.

Ariño Gil, E.; Dahí Elena, S. 2008, «Contextos cerámicos de la Antigüedad Tardía y la Alta Edad Media en la provincia de Salamanca (España)», Actes du Congrès de la Société Française d'Étude de la Céramique Antique en Gaule (Empúries, L'Escala, Espagne, mai 2008), Empúries, 265-276.

Balmaseda, L. J. 2006, «Ávila visigoda», J. Morín (ed.), La investigación arqueológica de la época visigoda en la Comunidad de Madrid. Zona Arqueológica 8 (1), 237-245.

Barraca De Ramos, P. 1998, «Poblamiento al sur del Duero en época tardía», R. Teja; C. Pérez (coords.), Actas Congreso Internacional La Hispania de Teodosio Vol. 2, Segovia, 353-360.

Barrio Martín, J. 1999, La Segunda Edad del Hierro en Segovia (España). Estudio arqueológico del territorio y la cultura material de los pueblos prerromanos. (B.A.R., Int. Ser., 790). Oxford.

Barrios García, A. 1983, Estructuras agrarias y de poder en Castilla. El ejemplo de Ávila (10851320) vol 1. Ávila.

Barrios García, A. 1984, Estructuras agrarias y de poder en Castilla. El ejemplo de Ávila (10851320), vol. 2. Ávila.

Barrios García, A. 2000, «Una tierra de nadie: los territorios abulense en la Alta Edad Media», en A. Barrios (coord.), Historia de Ávila II. Edad Media (siglos VIII-XIII), Ávila, 193-225.

Behre, K.-E. 1992, «The history of rye cultivation in Europe», Vegetation History and Archaeobotany 1, 141-156.

Bellido Blanco, A. 1997, «La ocupación de época visigoda en Vega de Duero (Villabáñez, Valladolid)», Archivo Español de Arqueología 70, $307-$ 316.

Bellido Blanco, A.; Cruz Sánchez, P. J. 1993, «Notas sobre el yacimiento protohistórico de Sieteiglesias (Matapozuelos, Valladolid)», F. Romero; C. Sanz; Z. Escudero (eds.) Arqueología Vaccea. Estudios sobre el Mundo Prerromano en la Cuenca Media del Duero, Valladolid, 263-277.

Blanco García, J. F. 1994, «El castro protohistórico de la Cuesta del Mercado (Coca, Segovia)», Cuadernos de Prehistoria y Arqueología de la Universidad Autónoma de Madrid 21, 35-80.

Blanco García, J. F. 1998, «Aproximación a la Cauca del Bajo Imperio», R. Teja; C. Pérez (coords.), Actas Congreso Internacional La Hispania de Teodosio Vol. 2, Segovia, 377-394.

Blanco García, J. F. 2002, «Coca. Cauca», T. Mañanes (ed.), Arqueología del Área Central de la Cuenca del Río Duero: de Simancas a Coca, Valladolid, 127-173.

Blanco García, J. F. 2003, Cerámica histórica en la provincia de Segovia. I Del Neolítico a época visigoda (V milenio - 711 d. C.) Segovia, NRT.

Blanco García, J. F. 2006, «El paisaje poblacional segoviano en época prerromana: ocupación del territorio y estrategias de urbanización», Oppidum $2,35-84$. 
Blanco González, A. 2008, «Tendencias del uso del suelo en el Valle Amblés (Ávila, España). Del Neolítico al Hierro Inicial», Zephyrus LXI, juliodiciembre.

Blanco González, A. e.p., «Tendencias del uso del suelo en el Valle Amblés (Ávila, España). De la Edad del Hierro al Medievo», Zephyrus LXII.

Caballero Arribas, J. 2001, Excavación arqueológica en La Cabeza de Navasangil. VillaviciosaSolosancho (Ávila). Informe Arqueológico. Escuela-Taller Ulaca II. Documento inédito depositado en el Servicio Territorial de Cultura de Ávila.

Chavarría, A. 2004-2005, «Romanos y visigodos en el valle del Duero (siglos V-VIII)» Lancia 6, 187-204.

Chavarría, A. 2006, «Villas en Hispania durante la Antigüedad tardía», Chavarría; J. Arce; G.P. Brogiolo (eds.), Villas Tardoantiguas en el Mediterráneo Occidental. Anejos de Archivo Español de Arqueología XXXIX, Madrid, 17-36.

Cheyette, F.L. 2008, «The Disappearance of the Ancient Landscape and the Climatic Anomaly of the Early Middle Ages: a Question to be Pursued», Early Medieval Europe 16 (2), 127-165.

Calleja Martínez, $M^{\text {a }}$.V. 2001, «El poblamiento de época visigoda en el sureste de la provincia de Valladolid», V Congreso de Arqueología Medieval Española (Valladolid, 1999), vol 1, 125-129.

Castellanos, S.; Martín Viso, I. 2005, «The local articulation of central power in the North of the Iberian Peninsula, 500-1000», Early Medieval Europe 13 (1), 1-42.

Centeno Cea, I. 2007, «La ciudad entre los siglos IV y VII. El mundo tardoantiguo», S. Estremera (coord.), Arqueología urbana en Ávila. La intervención en los solares del palacio de Don Gaspar del Águila y Bracamonte. Ávila, 115-137.

Clément, V. 2002, De la marche-frontière au paysdes-bois. Forêts, sociétés paysannes et territoires en Vieille-Castille ( $\mathrm{XI}^{e}-\mathrm{XX} \mathrm{X}^{e}$ siècle), Casa de Velázquez, Madrid.

Desprat, S.; Sánchez-Goñi, M.F.; Loutre, M.F. 2003, «Revealing climatic variability of the last three millennia in northwestern Iberia using pollen influx data». Earth and Planetary Science Letters 213, 63-78.

Díaz De La Torre, J. 2005, Informe final de la intervención arqueológica y puesta en valor del yacimiento de Los Henrenes o de San Cristóbal en Cillán (Ávila). $1^{a}, 2^{a}$ y $3^{a}$ fase. Documento inédito depositado en el Servicio Territorial de Cultura de Ávila.

Escalona Monge J. 2006, «Patrones de fragmentación territorial: el fin del mundo romano en la meseta del Duero», U. Espinosa; S. Castellanos (coords.), Comunidades locales y dinámicas de poder en el norte de la Península Ibérica durante la Antigüedad tardía, Logroño, 165-200.

Estremera, S. 2006, «La excavación arqueológica: una mirada a la historia de Ávila», S. Estremera (coord.), Arqueología urbana en Ávila. La intervención en los solares del palacio de Don Gaspar del Águila y Bracamonte. Ávila, 29-78.

Fabián García, J. F. 2003, «Ávila», Numantia 8, 271-279.

Fabián García, J. F. 2007, «Los orígenes de la ciudad de Ávila y la época antigua. Aportaciones de la Arqueología al esclarecimiento de las cuestiones históricas previas a la etapa medieval», Ávila en el tiempo. Homenaje al prof. Ángel Barrios. Institución Gran Duque de Alba, Ávila, vol. I, 83-110.

Fuentes Domínguez, A.; Barrio Martín, J. (1999): «Proyecto de investigación arqueológica en el Cerro de la Virgen del Castillo de Bernardos (Segovia)», P. Bueno; R. de Balbín (coords.), II Congreso de Arqueología Peninsular. Zamora Vol. 4, 441-450.

García Merino, C.; Sánchez Simón, M. 2001, «Excavaciones en la villa romana de Almenara-Puras (Valladolid): Avance de resultados (I)», Boletín del Seminario de Estudios de Arte y Arqueología 67, 99-124.

García Merino, C.; Sánchez Simón, M. 2004, «De nuevo acerca de la villa romana de Almenara de Adaja (Valladolid): excavaciones de 1998 a 2002», Archivo Español de Arqueología 77, 177-196.

Gómez Gandullo, J. 2006, «Avance sobre las excavaciones arqueológicas en el yacimiento de época visigoda de La Legoriza, San Martín del castañar (Salamanca)» en J. Morín (ed.), La investigación arqueológica de la época visigoda en la Comunidad de Madrid. Zona Arqueológica 8 (1), 216-235.

Gonzalo González, J. M. 2006, El Cerro del Castillo, Bernardos (Segovia). Un yacimiento arqueológico singular en la provincia de Segovia durante la Antigüedad Tardía. Segovia.

Gonzalo González, J. M. 2008, «Articulación del paisaje rural de época romana en la actual provincia de Segovia: el papel de las villae, C. Fernández Ochoa; V. García-Entero; F. Gil (eds.), Las villae tardorromanas en el occidente del Impero: arquitectura y función. Ediciones Trea, Gijón, 617-627. 
Guerra García, P. 2007, «Algunas notas sobre el contexto histórico visigodo en la provincia de Segovia», Zona Arqueológica 8 (1), 159-173.

Gutiérrez González, J. A. 2008, «Las villae y la génesis del poblamiento medieval», C. Fernández Ochoa; V. García-Entero; F. Gil (eds.), Las villae tardorromanas en el occidente del Impero: arquitectura y función. Ediciones Trea, Gijón, 216-238.

Gutiérrez Palacios, A.; Díaz, M.; Maluquer De Motes, J. 1958, «Excavaciones en la Lancha del Trigo, Diego Álvaro (Ávila)», Zephyrus IX, 59-78.

Hamerow, H. 2002, Early Medieval setllements. The Archaeology of Rural Communities in North-West Europe 400-900, Oxford.

Isla Frez, A. 2001, «Villa, villula, castellum. Problemas de terminología rural en época visigoda», Arqueología y Territorio Medieval 8, 9-19.

Juan Tovar, L. C.; Blanco García, J. F. 1997, «Cerámica común tardorromana, imitación de sigillata, en la provincia de Segovia. Aproximación al estudio de las producciones cerámicas del siglo $\mathrm{V}$ en la Meseta Norte y su transición al mundo hispano-visigodo», Archivo Español de Arqueología 70, 171-219.

Larrén, H.; Blanco, J. F.; Villanueva, O.; Caballero, J.; Domínguez, A.; Nuño, J.; Sanz, F. J.; Marcos, G. J.; Martín, M. A.; Misiego, J. 2003, «Ensayo de sistematización de la cerámica tardoantigua en la Cuenca del Duero», L. Caballero; P. Mateos; M. Retuerce (eds.), Cerámicas tardorromanas y altomedievales en la Península Ibérica. Ruptura y continuidad. Anejos de Archivo Español de Arqueología XXVIII. Mérida, 273-306.

Lewit, T. 2009, «Pigs, presses and pastoralism: farming in the fifth to sixth centuries AD» Early Medieval Europe 17 (1): 77-91.

López Quiroga, J. 2006, «Entre la villa y la aldea: arqueología del hábitat rural en Hispania (ss. V al VII)», J. López Quiroga; A.M. Martínez Tejera; J. Morín de Pablos (eds.), Gallia e Hispania en el contexto de la presencia 'germánica' (ss. VVII): Balances y Perspectivas. BAR IS 1534, Oxford, 19-60.

López Sáez, J. A.; López Merino, L. 2005, «Precisiones metodológicas acerca de los indicios paleopalinológicos de agricultura en la Prehistoria de la Península Ibérica», Portugalia 26, 53-64.

López Sáez, J. A.; López Merino, L.; Alba Sánchez, F.; Pérez Díaz, S. 2009, «Contribución paleoambiental al estudio de la trashumancia en el sector abulense de la Sierra de Gredos», Hispania LXIX, núm. 231, enero-abril, 9-38.

López Sáez, J.A. ; Van Geel, B. ; Farbos-Texier, S. ;
Diot, M.F. 1998, «Remarques paléoécologiques à propos de quelques palynomorphes non-polliniques provenant de sédiments quaternaires en France», Revue de Paléobiologie 17 (2), 445-459.

López Sáez, J.A.; Van Geel, B. ; Martín Sánchez, M. 2000, «Aplicación de los microfósiles no polínicos en Palinología Arqueológica», V. Oliveira Jorge (coord. ed.): Contributos das Ciências e das Technologias para a Arqueologia da Península Ibérica. Actas do $3^{\circ}$ Congresso de Arqueologia Peninsular, vol. IX, Vila-Real, Portugal, setembro de 1999, Oporto, 11-20.

Mariné, M. 1995, «La época romana», M. Mariné (coord.), Historia de Ávila. I. Prehistoria e Historia Antigua, Ávila, 281-338.

Martín Viso, I. 2006, «Tributación y escenarios locales en el centro de la Península Ibérica: algunas hipótesis a partir del análisis de las pizarras visigodas», Antiquité Tardive 14, 263-290.

Martín Viso, I. 2007a, «Tumbas y sociedades locales en el centro de la Península Ibérica en la Alta Edad Media: el caso de la comarca de Riba Côa (Portugal)», Arqueología y Territorio Medieval 14, 21-48.

Martín Viso, I. 2007b, «La sociedad rural en el suroeste de la meseta del Duero (siglos VI-VII)», en G. del Ser Quijano e I. Martín Viso (eds.): Espacios de poder y formas sociales en la Edad Medi. Estudios dedicados a Ángel Barrios. Salamanca, 171-188

Martín Viso I. 2008, «La ordenación del territorio rural y la tributación en el Suroeste de la Meseta del Duero (siglos VI-VII)», en S. Castellanos, I. Martín Viso (eds.), De Roma a los bárbaros: poder central y horizontes locales en la cuenca del Duero, León: Universidad de León, 227-61.

Martín Viso I. e.p., «Un mundo en transformación: los espacios rurales en la Hispania post-romana (siglos V-VII)», en L. Caballero, y P. Mateos Cruz (eds.), Visigodos y Omeyas V. El territorio. Mérida.

Martín Viso, I.; Barrios García, A. 2000-2001, «Reflexiones sobre el poblamiento rural altomedieval en el Norte de la Península Ibérica», Studia historica. Historia medieval 18-19, 53-83.

Martínez Caballero, S. 2000, «Notas sobre la romanización del territorio segoviano». Segovia romana, Segovia, 9-42.

Martínez Peñarroya, J. 2003, Excavación arqueológica en la Pared de los Moros (Niharra, Ávila). Documento inédito depositado en el Servicio Territorial de Cultura de Ávila.

Nuño González, J. 2003: «La Huesa, Cañizal 
(Zamora): ¿Un asentamiento altomedieval en el 'desierto' del Duero?», Numantia 8, 137-194.

Pérez González, C.; Reyes Hernando, O 2005, «Las Pizarras, Coca (Segovia). Campaña de excavaciones 2003», Oppidum 1, 59-102.

Pérez González, C.; Reyes Hernando, O. 2007a, «Proyecto de investigación Las Pizarras (Cauca, Segovia): Campaña arqueológica del año 2006», Oppidum 3: 7-34.

Pérez González, C.; Reyes Hernando, O. 2007b, «Coca, la antigua Cauca», M. Navarro; J. J. Palao; M. ${ }^{\mathrm{a}}$ A. Magallón (coords.), Villes et territoires dans le bassin du Douro à l'époque romaine: actes de la table-ronde internationale (Bordeaux, septembre 2004). Diffusion de Boccard. Bordeaux, 149-170.

Presas Vías, M.; Domínguez Alonso, R. M.; Moreno Lete, E. 1994, «Excavaciones arqueológicas de urgencia en el Pago de La Huesa (Cañizal)», Anuario del Instituto de Estudios Zamoranos Florián Ocampo 1994, 43-57.

Quintana López, J.; Centeno Cea, I. 2006, «Una ciudad integrada en el orbe romano. Desde sus raíces hasta el final del altoimperio», S. Estremera (coord.), Arqueología urbana en Ávila. La intervención en los solares del palacio de Don Gaspar del Águila y Bracamonte. Ávila, 79-110.

Quirós Castillo, J.A.; Vigil-Escalera, A. 2006, «Networks of peasant villages between Toledo and Velegia Alabense, Northwesterns Spain (V-X centuries)». Archeologia medievale 33, 79-130.

Regueras Grande, F., Olmo, J. Del 1997, «La villa de Los Casares (Armuña, Segovia): propuestas de lectura», R. Teja; C. Pérez (coords.), Actas Congreso Internacional La Hispania de Teodosio Vol. 2, Segovia, 675-686.

Ruiz Zapata, B., Gil García, M. J., Dorado Valiño, M. 1996, «Climatic changes in the Spanish Central South during the last 3000 BP based on pollen analysis», A.N. Angelakis; A.S. Issar (eds.): Diachronic climatic impacts on Water Resources with Emphasis on Mediterranean Region, Springer-Verlag, Berlin, 9-23.

Serrano Noriega, R. 2007, Excavaciones arqueológicas en el yacimiento romano de El Vergel II (San Pedro del Arroyo, Ávila). Informe inédito depositado en el Servicio Territorial de Cultura de Ávila.
Strato, S.L. 2001, Laguna de los Casares. Trabajos arqueológicos en las obras de construcción de la AP conexión A-6 (Villacastín a Ávila). Vol I. Informe inédito depositado en el Servicio Territorial de Cultura de Ávila.

TIR 1993, Tabula Imperii Romani, Hoja K-30: Madrid, Caesaraugusta, Clunia. Madrid.

Vigil-Escalera, A. 2000, «Cabañas de época visigoda: evidencias arqueológicas del sur de Madrid: tipología, elementos de datación y discusión», Archivo Español de Arqueología 73, 223-252.

Vigil-Escalera, A. 2003a, «Arquitectura de tierra, piedra y madera en Madrid (ss. V-IX d. C.): variables materiales, consideraciones sociales», Arqueología de la Arquitectura 2, 287-291.

Vigil-Escalera, A. 2003b, «Cerámicas tardorromanas y altomedievales de Madrid», L. Caballero; P. Mateos; M. Retuerce (eds.), Cerámicas tardorromanas y altomedievales en la Península Ibérica. Ruptura y continuidad. Anejos de Archivo Español de Arqueología XXVIII. Mérida, 371-387.

Vigil-Escalera, A. 2006, «El modelo de poblamiento rural en la Meseta y algunas cuestiones de visibilidad arqueológica», J. López Quiroga; A.M. Martínez Tejera; J. Morín de Pablos (eds.), Gallia e Hispania en el contexto de la presencia 'germánica' (ss. V-VII): Balances y Perspectivas. BAR IS 1534, Oxford, 89-108.

Vigil-Escalera, A. 2007, «Granjas y aldeas tardoantiguas y altomedievales de la Meseta. Configuración espacial, socioeconómica y política de un territorio rural al norte de Toledo (ss. v-x d.C.)». Archivo Español de Arqueología 80, 239-284.

Vigil-Escalera, A. 2009, «El poblamiento rural del sur de Madrid y las arquitecturas del siglo VII» en L. Caballero, P. Mateos y $\mathrm{M}^{\mathrm{a}}$. Ángeles Utrero (eds.): El siglo VII frente al siglo VII. Arquitectura, Anejos de Archivo Español de Arqueología LI. Madrid, CSIC, 205-229.

Villar García, L. M. 1986, La Extremadura castellanoleonesa. Guerreros, clérigos y campesinos (7111252), Valladolid.

Wickham, C. 2005, Framing the Early Middle Ages. Europe and the Mediterranean, 400-800. Oxford.

Zamora Canellada, A. 1997, «Algunas reflexiones sobre el siglo x en la provincia de Segovia», Estudios Segovianos 38, no 95, 413-432. 